\title{
Conglomeration with Bankruptcy Costs: Separate or Joint Financing?*
}

\author{
Albert Banal-Estañol ${ }^{\dagger}$ and Marco Ottaviani $^{\ddagger}$
}

July 2010

\begin{abstract}
The paper analyzes the determinants of the optimal scope of incorporation in the presence of bankruptcy costs. Bankruptcy costs alone generate a non-trivial tradeoff between the benefit of coinsurance and the cost of risk contamination associated to joint financing corporate projects through debt. This tradeoff is characterized for projects with binary returns, depending on the distributional characteristics of returns (mean, variability, skewness, heterogeneity, correlation, and number of projects), the bankruptcy recovery rate, and the tax rate advantage of debt relative to equity. Our testable predictions are broadly consistent with existing empirical evidence on conglomerate mergers, spin-offs, project finance, and securitization.
\end{abstract}

Journal of Economic Literature Classification Codes: G32, G34.

Keywords: Bankruptcy, conglomeration, mergers, spin-offs, project finance.

${ }^{*}$ We thank Viral Acharya, Philip Bond, Patrick Bolton, Hans Degryse, Denis Gromb, Maria Gutierrez, Florian Heider, Roman Inderst, Hayne Leland, Fausto Panunzi, Sherrill Shaffer, Peter Norman Sørensen, Javier Suarez, Jean Tirole, Vish Viswanathan, Jeff Zwiebel, and seminar participants at Arizona, Barcelona, Duke, Gerzensee, Granada, London, Loughborough, Mannheim, Milan, the European Winter Finance Conference 2008, and the Foro de Finanzas 2009 for helpful feedback.

${ }^{\dagger}$ Department of Economics and Business, Universitat Pompeu Fabra and Department of Economics, City University of London, Northampton Square, London EC1V 0HB, UK. Phone: +44-20-7040-4576. E-mail: a.banal-estanol@city.ac.uk. Web: http://www.staff.city.ac.uk/a.banal-estanol.

${ }^{\ddagger}$ Kellogg School of Management, Northwestern University, 2001 Sheridan Road, Evanston, IL 60208-2013, USA. Phone: +1-847-467-0684. E-mail: m-ottaviani@northwestern.edu. Web: http://www.kellogg.northwestern.edu/faculty/ottaviani/homepage. 
Consider a firm that needs to finance a number of risky projects from a competitive credit market. The firm has the choice of financing the projects either separately with a number of independent loans or jointly with a single loan. With either financing regime, part of the returns are lost to bankruptcy costs when creditors do not obtain full repayment. So when is joint financing more profitable than separate financing? By answering this fundamental corporate finance question we can determine the profitability of:

- mergers, which combine cash flows and the financing of otherwise separate corporations;

- holding companies, which protect the assets of individual subsidiaries from creditors' claims against one of the subsidiaries;

- spin-offs, whereby divisions or subsidiaries are set up as independent corporations;

- project finance and securitization, according to which projects are financed through separate special purpose vehicles.

At least since Lewellen (1971), conventional wisdom in corporate finance has largely settled on the view that bankruptcy costs always generate positive financial synergies, so that joint financing is more profitable than separate financing. According to this view, conglomeration brings about a reduction in the probability of bankruptcy by allowing a firm to use the proceeds of a successful project to save an unsuccessful one which would have otherwise failed. By aggregating imperfectly correlated cash flows, the argument goes, joint financing should reduce expected bankruptcy costs and increase borrowing capacity. As aptly summarized by Brealey, Myers, and Allen's (2006, page 880) textbook, "merging decreases the probability of financial distress, other things equal. If it allows increased borrowing, and increased value from the interest tax shields, there can be a net gain to the merger."

In this paper, we amend this conventional view by revisiting the purely financial effects of conglomeration. We argue that bankruptcy costs alone create a non-trivial tradeoff for conglomeration, even abstracting from tax considerations and changes in borrowing capacity. While the literature has mostly focused on the coinsurance benefits of conglomeration, we characterize the risk contamination losses that result when the logic of the conventional argument is turned on its head. Through risk contamination, the failure of one project can drag down another successful project that is financed jointly, thus increasing the probability of bankruptcy. The additional bankruptcy costs associated with the project that is driven into bankruptcy would have been saved if the projects had been financed separately. Precisely because the dragged down project is otherwise healthy, risk contamination can be substantial. 
To illustrate the value of breaking up a conglomerate to avoid risk contamination losses, consider the spin-off of R. J. Reynolds Tobacco Company from Nabisco's food business in 1999. As Steven F. Goldstone, chairman and chief executive officer of RJR Nabisco, commented in the official news release, this sale "paves the way for us to separate the domestic tobacco business from the rest of our organization on a sound and prudent financial basis." Similar considerations led many commentators to favor a split of UBS during the recent financial crisis, as the troubled investment banking unit was dragging down the highly profitable private banking business. As suggested by the Financial Times, UBS benefited from coinsurance gains ("the main reason its investment bank had access to such cheap funding during the boom that led to such huge losses was because UBS had a high credit rating, supported by its private banking business") but ended up suffering the effects of riskcontamination ("the losses have prompted clients to withdraw cash from UBS's core wealth management business" ${ }^{1}$

To best understand the determinants of the tradeoff between coinsurance and risk contamination, we focus on the simplest setting in which each project has two possible realizations of returns, either low or high. In the baseline model we constrain financing to be obtained only through standard debt. The low return realization is insufficient to cover the initial investment outlay, thus generating the possibility of bankruptcy. Separate financing involves a number of nonrecourse loans. This means that when the repayment obligation on one loan is not met, creditors do not have access to the returns of other projects. Through joint financing, instead, the returns of multiple projects are conglomerated, so that bankruptcy costs are only incurred when the sum of the returns of the projects falls below the overall repayment obligation required by the creditors.

To develop an initial intuition, consider a setting with two ex ante identical and independent projects, as in the baseline specification of our model. If the projects are financed separately, each loan defaults when the corresponding project yields a low return. If, instead, the projects are financed jointly, default occurs if the per-project repayment obligation is higher than the average return of the two projects. Similar to the case of separate financing, default occurs if the returns of both projects are low (bottom-left realization of the joint distribution of returns in Figure 1) and does not occur if the returns of both projects are high (top-right realization). The key to the comparison with separate financing is whether

\footnotetext{
${ }^{1}$ See "UBS does not have luxury of time before it splits up," Financial Times, March 17, 2008, and "Integration loses its attraction," Financial Times, August 13, 2008.
} 


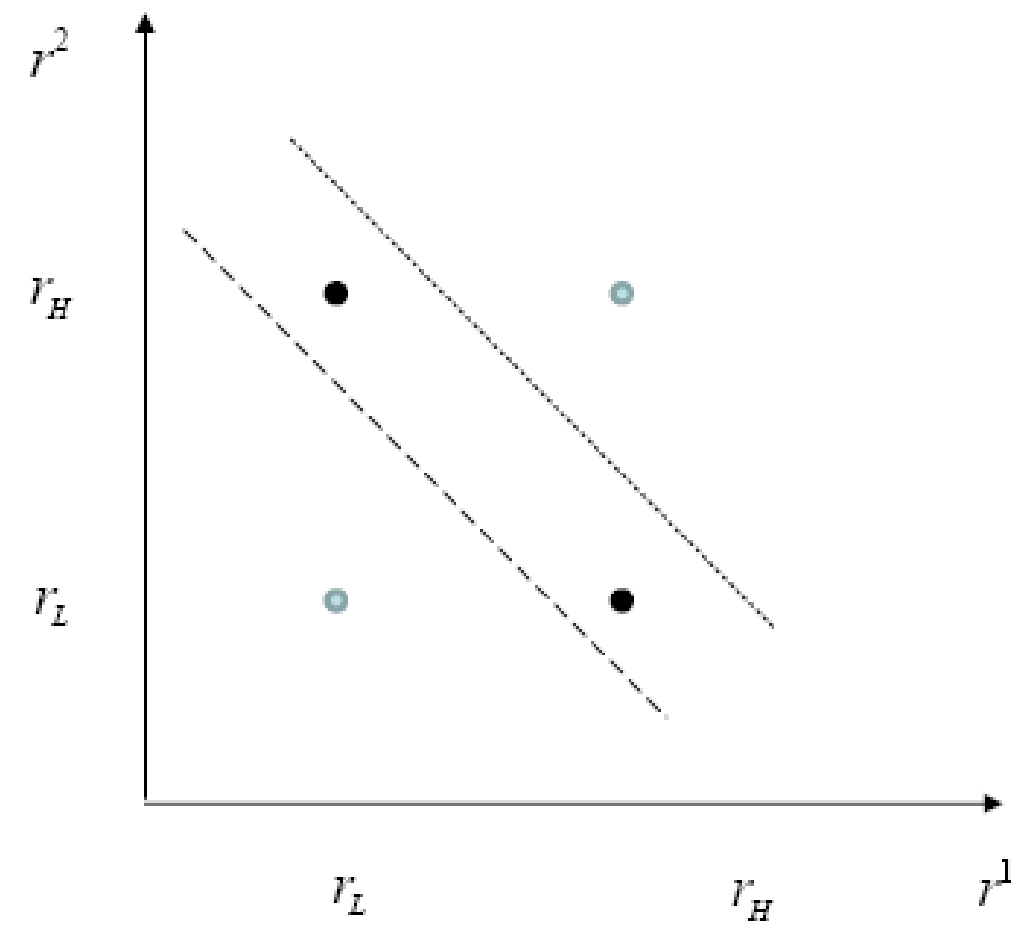

Figure 1. Joint distribution of returns. Each project $i=1,2$ yields an independent random return $r^{i}$ with a binary distribution. The return is either low, $r^{i}=r_{L}>0$, with probability $1-p_{i}$, or high, $r^{i}=r_{H}>r_{L}$, with probability $p_{i}$. 
or not the required repayment obligation can be met when one project yields a low return and the other project yields a high return, as illustrated by the top-left and bottom-right realizations in Figure 1. In turn, the repayment obligation is endogenously determined and depends on the financing regime. In either regime, competition forces creditors to set the repayment obligation at a level that allows the firm to obtain the projects' present value net of the expected bankruptcy costs.

There are two scenarios. First, suppose that the repayment obligation is below the average of the high and the low return, as illustrated by the dashed diagonal line in the figure. In this case, the probability of bankruptcy is reduced with joint financing. Ex post, a low-return project, which would have defaulted if it had been financed separately, is saved if the other project yields a high return. Ex ante, the two projects coinsure each other and the expected inefficiency associated with bankruptcy is reduced. A higher probability of full repayment forces creditors to reduce the repayment rates below the levels required under separate financing. This coinsurance effect drives the classic logic of "good" conglomeration stressed by Lewellen (1971).

This result is reversed if the per-project repayment obligation is above the average of the high and the low return, as illustrated by the dotted diagonal line in the figure. In this second scenario, the probability of bankruptcy is actually higher under joint financing! Ex-post, a high-return project, which would have stayed afloat if it had been financed separately, is now dragged into bankruptcy when the other project has a low return. Ex ante, projects riskcontaminate each other and the expected inefficiency associated with bankruptcy is increased with joint financing. If the bankruptcy recovery rate is low, competing creditors are forced to increase repayment rates above the level that results under separate financing because the loan will be repaid in full less often with joint financing. In this case, conglomeration is "bad" due to risk contamination.

The thrust of our analysis consists of deriving conditions on the exogenous parameters for good and bad conglomeration to arise. To this end, we first solve for the equilibrium repayment obligations that result in the two financing regimes, and then determine the region of parameters for which the borrower finds separate financing more profitable than joint financing. In the context of the baseline model with two identical and independent projects, we illustrate that separate financing can be optimal for empirically plausible parameter values and derive a number of testable comparative statics predictions, such as the following:

- A reduction in the bankruptcy recovery rate decreases the profitability of joint financ- 
ing. Given that the amount available to creditors following bankruptcy is lower when bankruptcy costs are higher, the repayment obligation associated with joint financing increases with the level of bankruptcy costs. It is then more difficult for the repayment obligation to be below the average of the high and the low return. Thus the profitability of joint financing is reduced. Consistent with this theoretical prediction, Rossi and Volpin (2004) show that improvements in judicial efficiency and creditor rights significantly increase M\&A activity and Subramanian, Tung, and Wang (2009) find that project finance is more likely than corporate finance in countries with less efficient bankruptcy procedures and weaker creditor rights.

- Joint financing is also less profitable when the projects are riskier, consistent with project finance being more widespread in riskier countries, as shown empirically by Kleimeier and Megginson (2000) among others.

- A mean-preserving increase in the negative skewness of the distribution of returns makes joint financing less likely. This result explains why projects with negatively skewed returns, due for example to environmental or expropriation risk, are likely to be financed on a project basis (see Esty (2003)).

In the discussion so far we have compared the profitability of separate and joint financing when both financing regimes are feasible. In the paper, we also characterize situations in which it is feasible to finance projects with positive net present value either only separately or only jointly. When the coinsurance effect prevails, joint financing increases the borrowing capacity, resulting in projects that can be financed jointly but cannot be financed separately. When risk contamination prevails, instead, joint financing decreases the borrowing capacity, so that there are projects that can be financed separately but not jointly.

The paper also derives a number of useful managerial implications. We show that a rule of thumb that prescribes adopting the financing regime associated with the lowest interest rate can result in suboptimal decisions. We illustrate situations in which it is more profitable for a firm to finance projects separately, even though joint financing at a lower interest rate is feasible. Indeed, joint financing can have lower repayment rates despite having a higher probability of bankruptcy. When the bankruptcy recovery rate is sufficiently high (or equivalently, bankruptcy costs are sufficiently low), at any given exogenous repayment rate, creditors expect to obtain more with joint financing than with separate financing because bankruptcy happens more often. As a result, competition forces creditors to offer a lower 
repayment rate to firms that finance projects jointly. This theoretical finding can explain why project finance is used despite the fact that "project debt is often more expensive than corporate debt," solving one of the "apparently counterintuitive features [of project finance]" (Esty (2003)).

Next, we turn to the case of projects with heterogeneous distributions of returns. The coinsurance and the risk contamination effects may be present simultaneously when two heterogeneous projects are financed jointly. We characterize situations in which a first project either saves or drags down a second project, depending on whether the first project succeeds or fails. This situation arises when projects differ in their riskiness, measured by secondorder stochastic dominance. We show that separate financing is relatively more profitable if the differences in terms of risk profiles of the two projects are higher. This is in line with empirical findings by Gorton and Souleles (2005) that riskier originator banks are more likely to securitize.

In addition, we show that an increase in correlation in project returns tends to favor separate financing. When projects' return are perfectly negatively correlated, the risk contamination effect is absent and the coinsurance effect is so strong so as to eliminate bankruptcy altogether when projects are financed jointly, as it is also intuitive. Exploiting the logic of the law of large numbers, we also show that when the number of projects becomes arbitrarily large it is optimal to finance them all jointly. Armstrong (1999) derives a similar result in the industrial organization literature on product bundling.

We also investigate the robustness of our results to different specifications for the structure of bankruptcy costs. In the baseline model, bankruptcy costs are proportional to the value of the assets under bankruptcy, as is commonly assumed in the theoretical and empirical literature. The logic of risk contamination also applies if, instead, bankruptcy costs depend on the number of projects that go bankrupt rather than on the value of assets under bankruptcy. Actually, we show that separate financing is then optimal for a larger set of parameters because it becomes easier to obtain joint financing, but only at the rate for which intermediate bankruptcy occurs. On the other hand, as it is intuitive to expect, joint financing is optimal for a larger set of parameters when there are economies of scale in bankruptcy costs, according to which per-project bankruptcy costs are lower when projects are financed jointly.

In the baseline model, we restrict financing to be obtained through debt. Note that debt is the optimal contractual arrangement if returns are privately observed by the borrower 
and can be verified by creditors only by inducing bankruptcy and incurring the bankruptcy costs. The optimality of debt follows immediately from a classic result derived by Townsend (1979), Diamond (1984), and Gale and Hellwig (1985) in the context of the costly state verification model. We also extend the analysis to allow financing through equity in addition to debt. As in the tradeoff theory of capital structure, equity saves on bankruptcy costs but is subject to higher taxation. When the possibility of equity financing is added, debt and equity are optimal contractual arrangements once we assume that equity investors are subject to higher taxation than debt, but are able to observe returns directly without the need of incurring verification/bankruptcy costs.

Turning to the choice of separate and joint financing in the model with debt and equity, we show that if the incremental tax on equity (or, equivalently, the tax advantage of debt) is sufficiently low, joint financing is inconsequential because bankruptcy can be avoided altogether with joint as well as with separate financing. More interestingly, if the tax differential is intermediate, joint financing is profitable in more cases than in the baseline model because, by using equity, it becomes possible to obtain a repayment rate that avoids default when one project yields a high return and the other project yields a low return. Finally, if the tax differential is sufficiently high, separate and joint financing are profitable in the same situations as in the baseline model, as no equity is used in either financing regime. In our model, when financing projects separately is strictly more profitable than financing them jointly, financing is exclusively in debt. Equity is more expensive and it is only used if it helps to obtain a repayment rate that decreases the probability of default, in which case joint financing is optimal. The exclusive use of debt in separate finance, which arises endogenously in our model, is consistent with the many empirical studies that find that a large proportion of funding in project finance is in the form of debt (see e.g. Kleimeier and Megginson (2000)).

In terms of the theoretical literature in corporate finance, we depart from Modigliani and Miller's (1958) world without financial synergies by introducing bankruptcy costs. In the absence of bankruptcy costs, joint and separate financing are equivalent (see, for example, Levy and Sarnat (1970)). By clarifying the conditions for the value of conglomeration in the presence of bankruptcy costs, this paper contributes to a voluminous literature on the analysis of purely financial motives for mergers. In his discussion to Lewellen (1971), Higgins (1971) notes that joint financing also affects the riskiness of the lender's returns; hence we abstract from risk concerns by assuming risk neutrality. Scott (1977) and Sarig (1985) show 
that if cash flows can be negative, a firm can exploit the shelter of limited liability by financing projects through separate corporations. In our analysis we explicitly abstract from this limited liability effect, so that the financing regime affects only the payoff of the firm and its creditors, without having any impact on the payoff of third parties. ${ }^{2}$

Our results are most closely related to three recent contributions. First, Winton (1999) studies whether financial institutions should specialize and lend to one sector or diversify and lend to several sectors. The third case of Winton's (1999) Proposition 3.1 discusses a situation in which a bank prefers to specialize even though a lower interest rate can be obtained through diversification. Our Proposition 4 uncovers conditions for a similar effect in the context of a simpler model. More generally, our paper unearths the logic and characterizes the more general tradeoff behind Winton's earlier example.

Second, Inderst and Müller (2003) (and Faure-Grimaud and Inderst (2005)) analyze financial conglomeration in a two-project version of Bolton and Scharfstein's (1990) dynamic model of debt. In their dynamic setting, financing two projects within the same corporation can reduce the firm's ability to borrow when the firm is able to finance follow-up investments internally without returning to the external capital market. In our model, bad conglomeration arises because of bankruptcy costs, a channel from which Inderst and Müller (2003) abstract.

Third, Leland (2007) compares the profitability of separate and joint financing for a borrower who trades off bankruptcy costs with tax shields by adjusting the mix of debt and equity. In the baseline version of our model, we consider fixed-investment projects that must be financed only with debt and thus we explicitly rule out the possibility of increasing leverage and re-optimizing the capital structure. Our analysis discovers situations in which separate financing is optimal even when the amount borrowed through debt does not depend on whether projects are financed jointly or separately. This result was not envisioned by Leland's (2007) numerical analysis, as explained in detail in Supplementary Appendix B. ${ }^{3}$

\footnotetext{
${ }^{2}$ A number of papers (e.g., Higgins and Schall (1975) and Kim and McConnell (1977)) have analyzed the effect of the current capital structure on merger incentives. These papers noted that, while mergers may increase total firm value, bondholders may gain at the expense of shareholders. We abstract from such a distributional conflict among (cashless) stakeholders, by considering the ex ante choice of corporate structure by shareholders and forcing bondholders to compete and therefore obtain no surplus.

${ }^{3}$ Our results are also very different from those of Shaffer (1994), who studies the effect of joint financing on the probability of joint failure. Instead, we compare the firm's expected payoff when the interest rate is endogenously determined by competition among creditors.
} 
The paper proceeds as follows. Section I formulates the model. Focusing on the baseline version of the model with two identically and independently distributed projects, financed with debt only, and with proportional bankruptcy rates, Section II analyzes the conditions setting apart good from bad conglomeration and performs comparative statics with respect to the distribution (mean, variance, and skewness) of returns and the bankruptcy recovery rate. Section III turns to the case of projects with heterogeneous returns. Section IV shows that an increase in the correlation of returns favors separate financing. Section $\mathrm{V}$ demonstrates that joint financing is optimal when the number of projects is sufficiently large. Section VI argues that our results are robust to how bankruptcy costs are modeled. Section VII extends the analysis to a setting in which equity is also available and is taxed at a higher rate than debt. Section VIII concludes with a summary and a discussion of avenues for future research. Appendix A collects the proofs omitted from the text. Supplementary Appendix B characterizes conditions for bad conglomeration to result in a variant of the model in which projects have continuous returns.

\section{Baseline Model}

This section formulates the simplest possible model to analyze how multiple projects should be optimally financed in the presence of bankruptcy costs. In the rest of the paper we derive results for special cases or extensions of this basic model.

A risk-neutral firm has access to $n$ projects. Project $i$ requires at $t=1$ an investment outlay normalized to $I=1$ and yields at $t=2$ a random payoff or return $r^{i}$ with a binary distribution: the return is either low, $r^{i}=r_{L}^{i}>0$, with probability $1-p_{i}$, or high, $r^{i}=r_{H}^{i}>$ $r_{L}^{i}$, with probability $p_{i}$. Each project has a positive net present value, $\left(1-p_{i}\right) r_{L}^{i}+p_{i} r_{H}^{i}-1>$ 0 . The low return is insufficient to cover the initial investment outlay, $r_{L}^{i}<1$. Returns are possibly correlated across projects.

Before raising external finance, the firm chooses how to group projects into corporations, or equivalently into separate nonrecourse loans. This means that investors in each corporation have access to the returns of all projects in that corporation, but they do not have access to the returns of the projects in the other corporations set up by the firm. Financing for each corporation can be obtained in a competitive credit market. For notational simplicity, we stipulate that the firm seeks financing only when expecting to obtain a strictly positive expected payoff.

Creditors are risk neutral and lend money through standard debt contracts. Without loss 
of generality we normalize the risk-free interest rate to $r_{f}=0 .{ }^{4}$ Therefore, creditors expect to make zero expected profits. This is equivalent to assuming that each corporation makes a take-it-or-leave-it repayment offer to a single creditor for each loan $j$, promising to repay $r_{j}^{*}$ at $t=2$ for each unit borrowed at $t=1 .^{5}$ Thus $r_{j}^{*}$ denotes the promised repayment per project. According to our accounting convention, the corporation's repayment obligation comprises the amount borrowed as well as net interest. ${ }^{6}$

Creditors are repaid in full when the total realized return of the projects pledged is sufficient to cover the promised repayment. If instead the total realized return falls short of the repayment obligation, the corporation defaults and the ownership of the projects' realized returns is transferred to the creditor. Following default, the creditor is only able to recover a fraction $\beta \in[0,1]$ of the realized returns $r$, so that the bankruptcy costs following default are equal to $(1-\beta) r$. The bankruptcy recovery rate $\beta$ measures the efficiency of the bankruptcy process and is industry specific. ${ }^{7}$ In Section VI, we analyze alternative specifications for bankruptcy costs which allow for fixed costs and economies of scale.

For the baseline specification of the model we restrict external financing to be obtained through debt. Note that debt is the optimal contractual arrangement if returns are privately observed by the borrower and can be verified by creditors only at a cost equal to the bankruptcy cost. This result follows immediately from classic analyses of the costly state verification model (see Townsend (1979), Diamond (1984), and Gale and Hellwig (1985)).

In Section VII, we extend the model to also allow for financing through tax-disadvantaged equity and we show that full debt financing is optimal if taxes are sufficiently high. In the context of that more general model, we characterize how the tradeoff between debt and equity influences the decision of whether projects should be financed separately or jointly. Until then we mute the choice between equity and debt and thus focus on the conglomeration decision when debt is the only source of financing that is available.

\footnotetext{
${ }^{4}$ To see that $I=1$ and $r_{f}=0$ are innocuous normalizations, suppose that the investment outlay is equal to $I$ and that the investors' required interest rate is $r_{f}>0$. Denoting the random cash flow by $R_{i}$, the project's return in the model can be reinterpreted in terms of percentage gross return for each unit of period-2 equivalent outlay: $r_{i}=R_{i} /\left[I\left(1+r_{f}\right)\right]$. Thus without loss of generality we can set $I=1$ and $r_{f}=0$.

${ }^{5}$ Thus, for the case in which each loan (or corporation) is financed by multiple creditors, we implicitly assume that there are no coordination failures across the creditors who syndicate the same loan.

${ }^{6}$ The net interest rate $i$ satisfies $1+i=r_{j}^{*}$ and therefore the repayment obligation can be interpreted as the gross interest rate.

${ }^{7}$ For estimates of bankruptcy costs and other costs of financial distress across industries see, for example, Warner (1977), Weiss (1990), and Korteweg (2007).
} 


\section{Two Identical and Independent Projects}

This section analyzes the simplest possible specification of the model to develop our main insight. The firm has access to two identically and independently distributed projects. Each project $i$ yields a low return $r_{L}^{i} \equiv r_{L}$ with probability $1-p_{i} \equiv 1-p$ and a high return $r_{H}^{i} \equiv r_{H}>r_{L}$ with probability $p_{i} \equiv p$.

In Section $\mathrm{A}$ we proceed to examine the conditions for when the borrower is able to finance the two projects separately and jointly. In Section B we compare the profitability of separate and joint financing, when they are both feasible. In Section $\mathrm{C}$ we illustrate that separate financing can be optimal for empirically plausible parameter values. In Section D we characterize the effect of conglomeration on the firm's borrowing capacity. In Section E we derive a set of comparative statics predictions for the occurrence of joint and separate financing. Finally, in Section $\mathrm{F}$ we show that the financing option with the lowest repayment rate is not necessarily optimal.

\section{A. Financing Conditions}

Consider first the possibility of financing the two projects through two separate nonrecourse loans or, equivalently, through two different limited liability corporations. Given that the two projects are ex ante identical, the financing of each project, if possible, takes place at the same rate. Such rate $r_{i}^{*}$ must satisfy $r_{L}<1<r_{i}^{*}<r_{H}$, so that there is a positive probability that the loan is not repaid in full. Indeed, the firm would not accept to be financed at a rate above $r_{H}$, because this would result in zero payoff for the firm. Also, the rate must be above 1 because at rates at or below 1 the creditor would make negative expected profits (by obtaining a return never above the investment outlay of 1 and strictly below 1 with strictly positive probability) and therefore would not be willing to extend the loan.

Given that the credit market is competitive, creditors must make zero expected profits. Thus the repayment requested by the creditor, $r_{i}^{*}$, is such that the gross expected proceeds, $p r_{i}^{*}+\beta(1-p) r_{L}$, are equal to the initial investment outlay 1. As a result, each project can be financed through a separate loan if and only if

$$
r_{i}^{*}:=\frac{1-\beta(1-p) r_{L}}{p} \leq r_{H}
$$

The repayment obligation, which is fully paid only in the case of a high return, is equal to 
the investment outlay, 1 , less the expected proceeds from bankruptcy, $\beta(1-p) r_{L}$, divided by the probability of staying afloat, $p$. Intuitively, the creditor needs to recover the expected shortfall in the event of bankruptcy from the event in which the project yields a high return. As a result, $r_{i}^{*}>1$.

Next, consider joint financing of the two projects through a single loan or, equivalently, within the same corporation. Denote by $r_{m}^{*}$ the equilibrium repayment obligation per unit of investment, so that $2 r_{m}^{*}$ is the total repayment promised to the creditor in return for the initial financing of the two projects, $2 I=2$. Two cases need to be distinguished, depending on whether or not the required repayment rate induces bankruptcy in the case with "intermediate returns," when one project yields a high return while the other project yields a low return.

Suppose first that the equilibrium repayment rate $r_{m}^{*}$ is such that $r_{L} \leq r_{m}^{*} \leq \frac{r_{H}+r_{L}}{2}$, so that there is no default with intermediate returns. As a result, the probability of default is reduced to $(1-p)^{2}$. Substituting again in the expected creditor profits, the borrower would only be able to obtain this rate in a competitive market if and only if

$$
r_{m}^{*}:=\frac{1-\beta(1-p)^{2} r_{L}}{1-(1-p)^{2}} \leq \frac{r_{H}+r_{L}}{2} .
$$

Suppose now that the equilibrium repayment rate $r_{m}^{* *}$ is such that $\frac{r_{H}+r_{L}}{2} \leq r_{m}^{* *} \leq r_{H}$ and therefore the borrower defaults in the event of a high and a low return. Hence, default occurs with probability $1-p^{2}$. In a competitive credit market, this rate can be obtained if and only if

$$
r_{m}^{* *}:=\frac{1-\beta(1-p)\left(p r_{H}+r_{L}\right)}{p^{2}} \leq r_{H}
$$

Since the borrower's expected profits for a given distribution are decreasing in the equilibrium rate, if both conditions (2) and (3) are satisfied, the borrower prefers rate $r_{m}^{*}$ to rate $r_{m}^{* *}{ }^{8}$ Summarizing the results so far, we have the following proposition.

Proposition 1: Two independent and identical projects can be financed separately if and only if condition (1) is satisfied, in which case the equilibrium rate is $r_{i}^{*}$. Projects can be financed jointly if and only if conditions (2) or (3) are satisfied. If condition (2) is satisfied, the equilibrium rate is $r_{m}^{*}$, and if it is not satisfied, the equilibrium rate is $r_{m}^{* *}$.

\footnotetext{
${ }^{8}$ It is straightforward to show that if $r_{m}^{*}>\left(r_{H}+r_{L}\right) / 2$, then $r_{m}^{* *}>\left(r_{H}+r_{L}\right) / 2$. Therefore, if it is not possible to obtain $r_{m}^{*}$, then we can disregard the $r_{m}^{* *}>\left(r_{H}+r_{L}\right) / 2$ constraint.
} 
Figure 2 depicts how per-project expected returns are divided between the borrower and the creditor in the three scenarios described by Proposition 1. The project's expected return is equal to the area above the distribution function (and up to 1). When the two projects are financed separately, the return of each project is a binary random variable with a cumulative distribution represented in Panel (a). When the two projects are bundled and financed jointly, there are three possible realized returns. Panels (b) and (c) display the cumulative distributions of the (per-project) returns resulting from joint financing for two different examples. In each graph the dashed distribution corresponds to the returns resulting from separate financing. Note that the distribution of (per-project) returns with separate financing is a mean-preserving spread of the distribution with joint financing. Intuitively, joint financing steepens the return distribution around the center, $\left(r_{H}+r_{L}\right) / 2$, by inducing an anti-clockwise rotation.

For any given repayment rate $r$, the net expected return for the borrower in the three panels corresponds to the area above the cumulative distribution of (per-project) returns at $r, F(r)$, and to the right of $r$ (in light gray). The gross expected return of the creditor is the sum of (i) the area above $F(r)$ and to the left of $r$ (in gray) and (ii) a fraction $\beta$ of the area below $F(r)$ and above the distribution function (in black). The area (i) is equal to $p r$, which is the full repayment of the outstanding obligation multiplied by the probability that the project stays afloat. The area (ii) is equal to $\beta(1-p) r_{L}$, capturing the expected returns obtained in case of bankruptcy. The remaining fraction $1-\beta$ of the black area is equal to the expected bankruptcy costs. This is also equal to the difference between the net present value of the firm, the area above the distribution function and below 1 , and the sum of creditor's and borrower's profits.

The equilibrium rate $r^{*}$ in the three panels is such that the gross expected return of the creditor is equal to 1. Projects can be financed separately as long as the creditor's gross returns at a rate $r_{H}$ are greater than 1, as in Panel (a). Projects can be financed jointly at a rate that avoids intermediate bankruptcy as long as the per-project creditor returns at the center or crossing point, $\left(r_{H}+r_{L}\right) / 2$, are greater than 1, as in Panel (b). Projects can only be financed jointly at a rate that does not avoid intermediate bankruptcy if the per-project creditor returns at $\left(r_{H}+r_{L}\right) / 2$ are lower than 1 and at $r_{H}$ are greater than 1 , as in Panel (c). 

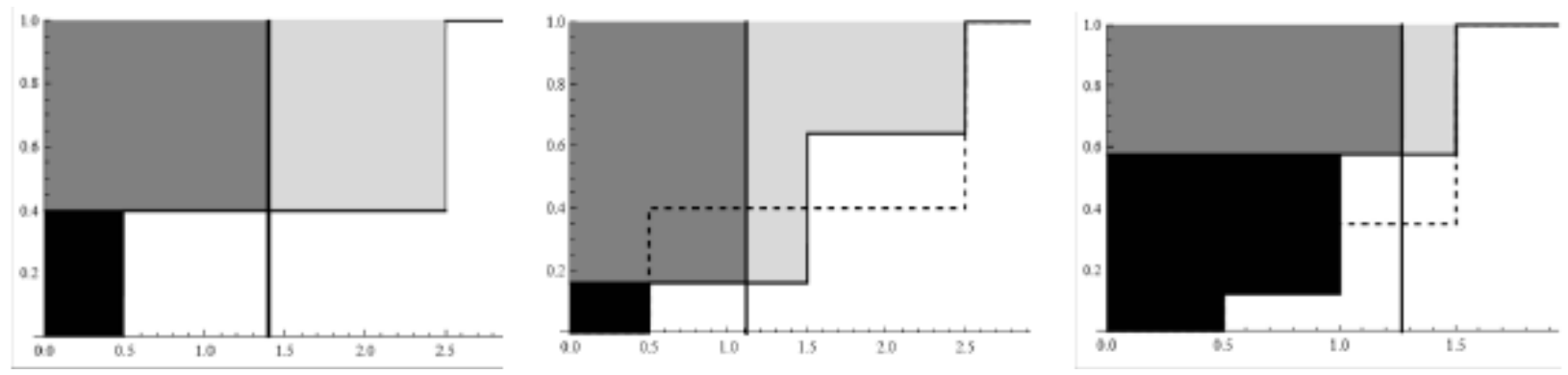

Figure 2. Distribution of Returns. The area above the distribution function represents the project's expected return. For a given repayment rate $r$, the net expected return for the borrower corresponds to the area above the distribution function and to the right of $r$ (in light gray). The gross expected return for the creditor is the sum of (i) the area above $F(r)$ and to the left of $r$ (in gray) and (ii) a fraction $\beta$ of the area below $F(r)$ and above the distribution function (in black). The equilibrium rate $r^{*}$ is such that the gross expected return for the creditor is equal to 1 . Projects can be financed separately if the creditor's gross expected return at the rate $r_{H}$ is greater than 1 , as in Panel (a). Projects can be financed jointly at a rate below the crossing point if the per-project creditor returns at $\left(r_{H}+r_{L}\right) / 2$ are greater than 1 , as in Panel (b). Projects can only be financed jointly at a rate above the crossing point if the creditor's per-project returns at $\left(r_{H}+r_{L}\right) / 2$ are smaller than 1 and at $r_{H}$ are greater than 1, as in Panel (c). The parameters used in panels (a) and (b) are $p=0.6, r_{L}=0.5, r_{H}=2.5$ and $\beta=0.8$ and in panel (c) $p=0.65, r_{L}=0.5$, $r_{H}=1.5$ and $\beta=0.9$. 


\section{B. Good and Bad Conglomeration}

When both separate and joint financing are feasible, which regime is more profitable and thus optimal for the borrower? Obviously, in the absence of bankruptcy costs (i.e., when $\beta=1$ ) the borrower is indifferent between financing the projects separately or jointly. The next proposition states the gains and losses when $\beta<1$.

Proposition 2: When the borrower can finance two independent and identical projects separately as well as jointly:

(a) If condition (2) is satisfied, it is optimal to finance the projects jointly to enjoy the coinsurance gains: $p(1-p)(1-\beta) r_{L}$.

(b) If condition (2) is not satisfied, it is optimal to finance the projects separately to avoid the risk contamination losses: $p(1-p)(1-\beta) r_{H}$.

Intuitively, when the borrower obtains a rate that avoids intermediate bankruptcy, the probability of default under joint financing is lower than under separate financing. The lowreturn project is saved from default when the other project yields a high return, thereby reducing the inefficiency associated with bankruptcy. Per-project expected savings when the projects are financed jointly rather than separately - the "coinsurance effect" — are equal to the probability that the first project yields a low return while the second project yields a high return, $p(1-p)$, multiplied by the losses avoided due to bankruptcy costs, $(1-\beta) r_{L}$. Graphically, per-project savings due to the coinsurance effect associated with joint financing are represented by a fraction $(1-\beta)$ of the dark gray area in Panel (a) of Figure 3.

If, instead, the borrower obtains a joint rate that does not avoid intermediate bankruptcy, a project with low return drags down the other project, increasing the probability of default. Per-project expected losses when projects are financed jointly rather than separately - the "risk contamination effect" — are equal to the probability that the first project yields a high return while the second project yields a low return, $p(1-p)$, multiplied by the additional losses in bankruptcy costs incurred, $(1-\beta) r_{H}$. Graphically, the per-project costs due to the risk contamination effect associated with joint financing are represented by a fraction $(1-\beta)$ of the darker gray area in Panel (b) of Figure 3.

The key is whether the equilibrium repayment rate for joint financing is below or above the crossing point, $\left(r_{H}+r_{L}\right) / 2$. Notice that the crossing point is not necessarily at the mean. In particular, if $p>1 / 2$, so that the distribution is skewed to the left (i.e., returns 

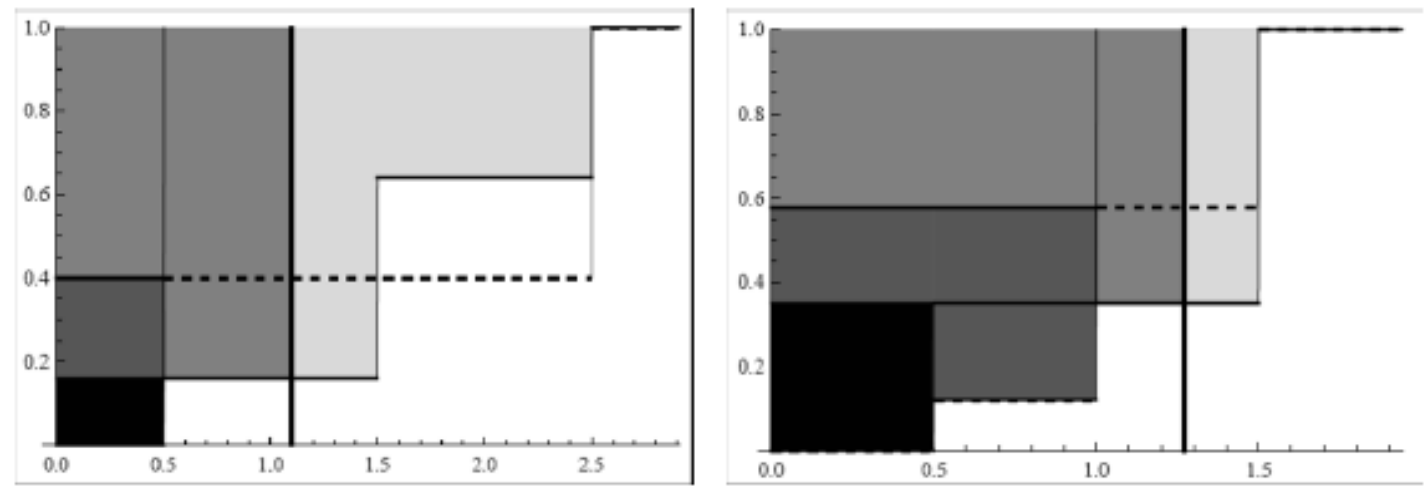

Figure 3. Good and Bad Conglomeration. Panel (a): Projects can be financed jointly at a rate below the crossing point. The reduction in expected bankruptcy costs obtained with joint rather than separate financing (co-insurance effect) is equal to the darker gray area. Panel (b): Projects cannot be financed jointly at a rate below the crossing point. The increase in expected bankruptcy costs obtained with joint rather than separate financing (risk contamination effect) is equal to the darker gray area. The parameters used in panel (a) are $p=0.6, r_{L}=0.5, r_{H}=2.5$ and $\beta=0.8$ and in panel (b) $p=0.65, r_{L}=0.5, r_{H}=1.5$ and $\beta=0.9$.

are negatively skewed), the crossing point is below the mean. As a result, equilibrium rates above the crossing point are consistent with a probability of default below $50 \%$. The resulting default probabilities would be $1-p$ for separate financing and $1-p^{2}$ for joint financing, which for a high enough $p$ may be very low, as illustrated in the following numerical example.

\section{Illustration}

We now illustrate how conglomeration can result in an increase in expected bankruptcy costs for empirically plausible parameter values under the maintained assumption that returns are binary. To this end, Figure 4 reports a calibration of the four parameters $\left(r_{H}, r_{L}\right.$, $p$, and $\beta$ ) of the baseline version of the model with separate financing. As representative values, we set:

(i) the probability of bankruptcy at $10 \%$ by using Longstaff, Mittal, and Neis (2005) estimate for bonds by BBB rated firms with a five-year horizon;

(ii) the internal rate of return at an average of $15 \%$ and $20 \%$;

(iii) the bankruptcy recovery rate at 65\% from Alderson and Betker (1995); and

(iv) bankruptcy costs as a fraction of a firm's value at 10\%, at the low end of Altman's 


\begin{tabular}{|l|l|l|}
\hline VARIABLE & PARAMETRIZATION & VALUE \\
\hline Probability of bankruptcy & $1-p$ & 0.10 \\
\hline Internal rate of return & $\frac{p r_{H}+(1-p) \beta r_{L}-1}{1}$ & 0.175 \\
\hline Bankruptcy recovery rate & $\beta$ & 0.65 \\
\hline Bankruptcy costs as a fraction of firm's value & $\frac{(1-\beta) r_{L}}{p r_{H}+(1-p) \beta r_{L}}$ & 0.10 \\
\hline
\end{tabular}

Figure 4. Parameter Calibration.

(1984) estimate of $11-17 \%$ for bankruptcy costs as a fraction of firm value up to three years before default and more conservative than Korteweg's (forthcoming) estimate of $15-30 \%$ of firm value at the point of bankruptcy.

The calibrated values are $r_{H}=1.28 ; r_{L}=0.34 ; p=0.9 ; \beta=0.65$, for which it is feasible to finance the projects separately, since $r_{i}^{*}=1.09<1.28=r_{H}$, as well as jointly, since $r_{m}^{* *}=1.12<1.28=r_{H}$, but not at the rate below the crossing point, because $r_{m}^{*}=1.01>$ $0.81=\left(r_{H}+r_{L}\right) / 2$. Thus, separate financing is more profitable than joint financing. In this illustration, the risk contamination effect identified in Proposition 2 is $p(1-p)(1-\beta) r_{H}=$ $0.04,4 \%$ of the investment outlay $I=1$, corresponding to $0.04 / 0.175 \approx 23 \%$ of the project's net present value.

\section{Borrowing Capacity}

So far we have compared the profitability of separate and joint financing when both financing regimes are feasible. As we have seen in Section A, there are situations in which it is feasible to finance projects with positive net present value either only separately or only jointly. Thus, conglomeration does not necessarily increase the firm's ability to finance projects.

Proposition 3: Consider two identical and independent projects:

(a) If condition (2) is satisfied, there are projects that can be financed jointly but not separately.

(b) If condition (2) is not satisfied, any project that can be financed jointly can be financed separately and there are projects that can only be financed separately.

When the coinsurance effect prevails, there are projects that can be financed jointly 
but cannot be financed separately. In this first case, conglomeration increases the firm's borrowing capacity, as in Lewellen (1971). However, when risk contamination prevails, joint financing decreases the firm's borrowing capacity, so that there are projects that can be financed separately but not jointly.

\section{E. Testable Predictions}

We now derive comparative statics predictions with respect to changes in the characteristics of the projects: the recovery rates and the distribution of returns (mean, variability, and skewness). For each attribute, we study whether separate or joint financing is optimal for a larger range of the remaining parameters. Again, the key aspect is whether it is easier or more difficult to obtain a repayment rate for joint financing below the crossing point. In turn, this depends on how parameter changes affect the crossing point as well as the returns the firm can pledge to the creditors at that point.

At the same time, we contrast our predictions with those from existing theories and discuss how our predictions on joint and separate financing match existing empirical evidence. Support for the desirability of joint financing can be found on the occurrence of mergers, especially conglomerate mergers, whereas support for separate financing can be found in spin-offs. As also argued by Leland (2007), structured finance, and in particular asset securitization and project finance, are other means to separate activities from originating or sponsoring organizations. A bankruptcy-remote special purpose entity or vehicle (SPE or SPV) raises funds to compensate the sponsor by selling securities that are collateralized by the cash flows of the transferred assets. From an analytical perspective, these entities have the key features of a separate corporations.

Prediction 1: For higher bankruptcy costs (lower $\beta$ ) then (a) both joint and separate financing can be obtained for a smaller region of parameters and (b) joint financing is optimal for a smaller region of the remaining parameters.

Higher bankruptcy costs decrease pledgeable returns (the sum of the gray, and a fraction $1-\beta$ of the black area in Figure 1), since the recovered returns in case of default are lower (higher discount in the black area). Since the bankruptcy costs do not affect the crossing point, $\left(r_{H}+r_{L}\right) / 2$, financing at a rate that avoids intermediate bankruptcy is more difficult and thus joint finance is less likely. To the best of our knowledge, this prediction had not been formulated before. 
Still, this prediction is consistent with the empirical evidence that suggests that merger activity is less likely and project finance more likely in countries with weaker investor protection. Rossi and Volpin (2004) show that improvements in judicial efficiency and creditor rights significantly increase M\&A activity. Comparing the incidence of bank loans for project finance with regular corporate loans for large investments, Subramanian, Tung, and Wang (2009) show that project financing is more likely in countries with less efficient bankruptcy procedures and weaker creditor rights. Both measures of investor protection decrease bankruptcy costs and should make, according to our model, separate financing (project finance) less likely and joint financing (mergers) more likely.

Prediction 2: For higher probability of a high return (higher $p$ ) then (a) both joint and separate financing can be obtained for a larger region of parameters and (b) joint financing is optimal for a larger region of the remaining parameters.

If the probability of a high return increases, it becomes easier to finance projects as well as to finance at a repayment rate that avoids intermediate bankruptcy. Graphically, this lowers all the horizontal lines in Figure 2, thereby increasing the expected value, the area above the distribution, without affecting the crossing point. Financing is eased and, in particular, financing at a rate that avoids intermediate bankruptcy, because the expected return pledgeable to creditors also increases.

This prediction contrasts with that of Inderst and Müller (2003). In their model, better projects are better kept separate to avoid self-financing and thus commit to return to the capital market. The two effects might explain the conflicting empirical evidence on the productivity of conglomerate firms. While Maksimovic and Phillips (2002) find that conglomerate firms, for all but the smallest firms in their sample, are less productive than single-segment firms, Schoar (2002) finds that the productivity of plants in conglomerate firms is higher than in stand-alone firms. ${ }^{9}$

During booms, projects might have a higher expectation across-the-board. Our prediction

\footnotetext{
${ }^{9}$ Still, Shoar (2002) finds that conglomerates are less valued than focused firms (the so-called market diversification discount), and argues that the discrepancy can be attributed to conglomerates leaving more rents to workers. A number of papers have also argued that the diversification discount could also be spurious, because of measurement problems and selection biases. For example, Graham, Lemmon and Wolf (2002) show that acquirers' excess values decline because the business units acquired are already discounted, thus explaining the diversification discount with a self-selection argument. See also Campa and Kedia (2002), Villalonga (2004), and Custodio (2009).
} 
would then be consistent with a large body of empirical evidence that shows that merger activity usually heats up during economic booms and slows down in recessions (see, for example, Maksimovic and Phillips (2001)). Similarly, Cantor and Demsetz (1993) show that off-balance sheet activity (separate financing) grows following a recession.

Prediction 3: Consider the effect of a mean-preserving spread in the project's return consisting of an increase in the high return $r_{H}$ and a reduction in the low return $r_{L}$ so as to maintain the mean return constant. Then, there exists $\bar{p}<1 / 2$ such that the region of parameters for which joint financing is optimal decreases if and only if $p>\bar{p}$.

That is, a mean preserving spread in the distribution of returns favors separate financing as long as the distribution of returns is not too positively skewed. If the distribution is symmetric $(p=1 / 2)$, a mean preserving spread increases $r_{H}$ by as much as it reduces $r_{L}$. While the crossing point is unaffected, the joint financing rate that avoids intermediate bankruptcy becomes more difficult to obtain because the low return is even lower and the pledgeable returns before the crossing point are lower. In the graph, the black area shrinks. If the distribution of returns is negatively skewed $(p>1 / 2)$, the crossing point is decreased and it becomes even more difficult to obtain joint financing below the crossing point. ${ }^{10}$

This prediction is consistent with a similar prediction obtained in Leland (2007). Empirical support can be found in the project finance literature. Kleimeier and Megginson (1999), for example, find that project finance loans are far more likely to be extended to borrowers in riskier countries, particularly countries with higher political and economic risks. They claim that: "As a whole, these geographic lending patterns are consistent with the widely held belief that project finance is a particularly appropriate method of funding projects in relatively risky (non-OECD) countries."

Prediction 4: Consider the effect of a mean-preserving increase in negative skewness in the project's return consisting of a reduction in the low return level $r_{L}$ and an increase in the probability of high return $p$ so as to maintain the mean return constant. Then, it becomes optimal to finance the projects jointly for a smaller region of parameters if and only if the high return level $r_{H}$ is sufficiently large.

\footnotetext{
${ }^{10}$ To maintain the mean constant, a given increase in $r_{H}$ must be combined with a larger decrease in $r_{L}$, resulting in a reduction in the crossing point. Formally, from $r_{H}^{\prime}=r_{H}+\varepsilon$ and $r_{L}^{\prime}=r_{L}-\varepsilon p /(1-p)$, we have $\left(r_{H}^{\prime}+r_{L}^{\prime}\right) / 2=\left(r_{H}+r_{L}\right) / 2-\varepsilon(2 p-1) / 2(1-p)$.
} 
An increase in the negative skewness has two conflicting effects. On the one hand, as $r_{L}$ decreases the crossing point is reduced and the returns in case of bankruptcy are lower, so that joint financing at the rate that avoids intermediate bankruptcy becomes more difficult. On the other hand, as $p$ increases so as to keep the mean constant, the probability that both projects' returns are low is reduced, so that it becomes easier to finance the projects at the rate avoiding intermediate bankruptcy. Graphically, the black area (creditor's expected returns in case of default) becomes less wide and less high and the gray area (creditor's expected returns if staying afloat) is less wide but also higher at the crossing point. If $r_{H}$ is sufficiently high, the first effect dominates and separation is more likely to be optimal. Indeed, for a given increase in $p$, one needs a higher reduction in $r_{L}$ to ensure a constant mean.

We can find support for this prediction in the literature on project finance and hedge funds. Esty (2003) shows that project finance is used when the possibility of total loss exists, due to environmental and expropriation risks. This type of risks generate returns with large negative skewness, as opposed to other type of risks such as exchange rate, throughput, quantity or price risks, which can go either way. Hedge funds returns also have negative skewness and, at the same time, they make heavy use of off-balance sheet instruments. Indeed, Brooks and Kat (2002) and Malkiel and Saha (2004) show that hedge fund indices exhibit considerable negative skewness. At the same time, hedge funds rely heavily on off-balance sheet techniques. For example, before its demise in 1990, Long Term Capital Management's balance sheet amounted to $\$ 125$ billion but its off-balance sheet positions had a notional amount of $\$ 1.25$ trillion.

\section{F. $\quad$ Managerial Implications}

We now show that the option with the lowest repayment rate does not necessarily entail the lowest likelihood of bankruptcy and is thus not necessarily optimal. Thus borrowers would be misguided by choosing the financing regime that leads to the lowest interest rate. The following proposition characterizes when it is more profitable to finance projects separately, even though joint financing is available at a lower rate.

Proposition 4: Separate financing is optimal even though it results in higher repayment rates if and only if (i) condition (3) is satisfied but condition (2) is not satisfied and (ii) $\beta\left[p r_{H}+(1-p) r_{L}\right]>1$. 
Suppose that the borrower has the choice of financing the projects independently and jointly, although only at a rate with intermediate bankruptcy. In this region, the low return project drags down the high-return project and it is more profitable to finance projects separately. Joint financing, however, can have lower repayment rates despite having a higher probability of bankruptcy. When the bankruptcy recovery rate is sufficiently high (or equivalently, bankruptcy costs sufficiently low), at any given exogenous repayment rate creditors expect to obtain more with joint financing because bankruptcy happens more often and they thus offer lower rates. The borrower might feel tempted to finance the projects jointly, but this is suboptimal. Low interest rate associated with joint financing here are deceptively attractive. Even though conglomeration looks good, it is unambiguously bad.

The logic can be further illustrated by Panel (b) of Figure 3. For an (exogenous) repayment rate above the crossing point, $r>\left(r_{H}+r_{L}\right) / 2$, as the one depicted, the creditor's expected returns might be higher if projects are financed jointly in spite of the increased occurrence of bankruptcy. Indeed, with joint financing, the creditor obtains the part of the gray area above the dashed line as well as a fraction $\beta$ of the dark gray and black areas. With separate financing, the creditor obtains the gray area, the upper part of the dark gray area and a fraction $\beta$ of the black area. Subtracting, the creditor's returns are higher if proceeds from the fraction $\beta$ of the dark gray area, $p(1-p) \beta r_{H}$, are greater than the sum of the upper part of the dark gray area and the part of the gray area below the dashed line, $p(1-p) r$. That is, if and only if $\beta r_{H}>r$. If this condition is satisfied by the equilibrium rate with separate financing, $\beta r_{H}>r_{i}^{*}$ (as in the statement of the proposition), the equilibrium rate with joint financing must be lower, $r_{m}^{* *}<r_{i}^{*}$, despite a higher probability of bankruptcy. Intuitively, creditors obtain higher proceeds from a bankrupt high value project than what they can charge for separate loans. So, they are forced by competition to offer lower interest rate. Thus, the borrower obtains a higher expected payoff with separate financing at a higher interest rate. ${ }^{11}$

\footnotetext{
${ }^{11}$ Note if the distribution of returns was continuous (as in the extension considered in Supplementary Appendix B), the extra losses from higher probability of bankruptcy if the equilibrium rate with joint financing were marginally above the crossing point would always be compensated by the increased proceeds from bankruptcy. Therefore, interest-rate reducing but profit-reducing conglomeration always appears when the project's returns are continuously distributed, because then there would be no discrete jump in the probability of bankruptcy at the crossing point (as there is with binary returns).
} 


\section{Heterogeneous Projects}

So far, we have assumed that projects are ex ante symmetric. In this section, we extend the baseline setup to allow for heterogeneity across projects. Project $i, i=1,2$, yields (independent) returns $r_{H}^{i}$ with probability $p_{i}$ and $r_{L}^{i}$ with probability $1-p_{i}$. Without loss of generality, assume that $r_{H}^{1}+r_{L}^{2}>r_{L}^{1}+r_{H}^{2}$, interchanging the indices if necessary. With heterogeneous projects, four (rather than three) levels of combined returns are possible, adding an extra case to the conditions for joint financing. Now, the possibility arises that default is avoided if project 1 yields a high return and project 2 a low return, whereas default is not avoided if the reverse occurs.

\section{A. Financing Conditions}

Projects can be financed separately if they individually satisfy condition (1), as in the homogeneous case. In the case of joint financing, there are now three conditions and there possible rates. As in the baseline setup, there exists $r_{m}^{\prime}$ such that bankruptcy can be avoided if one project's return is high and the other is low, which can be obtained if and only if ${ }^{12}$

$$
r_{m}^{\prime}\left(p_{1}, p_{2}, r_{L}^{1}, r_{L}^{2}, r_{H}^{1}, r_{H}^{2}, \beta\right) \leq \frac{r_{L}^{1}+r_{H}^{2}}{2} .
$$

If projects are heterogenous, there exists $r_{m}^{\prime \prime}$ such that bankruptcy can be avoided if project 1 's return is high and project 2's is low but not viceversa, which can be obtained if and only if

$$
r_{m}^{\prime \prime}\left(p_{1}, p_{2}, r_{L}^{1}, r_{L}^{2}, r_{H}^{1}, r_{H}^{2}, \beta\right) \leq \frac{r_{H}^{1}+r_{L}^{2}}{2} .
$$

Finally, as in the baseline case, there exists $r_{m}^{\prime \prime \prime}$ such that bankruptcy cannot be avoided if any of the two projects' return is low, which can be obtained if and only if

$$
r_{m}^{\prime \prime \prime}\left(p_{1}, p_{2}, r_{L}^{1}, r_{L}^{2}, r_{H}^{1}, r_{H}^{2}, \beta\right) \leq \frac{r_{H}^{1}+r_{H}^{2}}{2} .
$$

Summarizing the results so far, we have the following proposition.

Proposition 5: Two heterogeneous projects can be financed jointly if and only if conditions (4), (5) or (6) are satisfied.

(a) If condition (4) is satisfied, the equilibrium rate is $r_{m}^{\prime}$;

\footnotetext{
${ }^{12}$ The precise expression is included in the Appendix, in the proof of Proposition 5.
} 


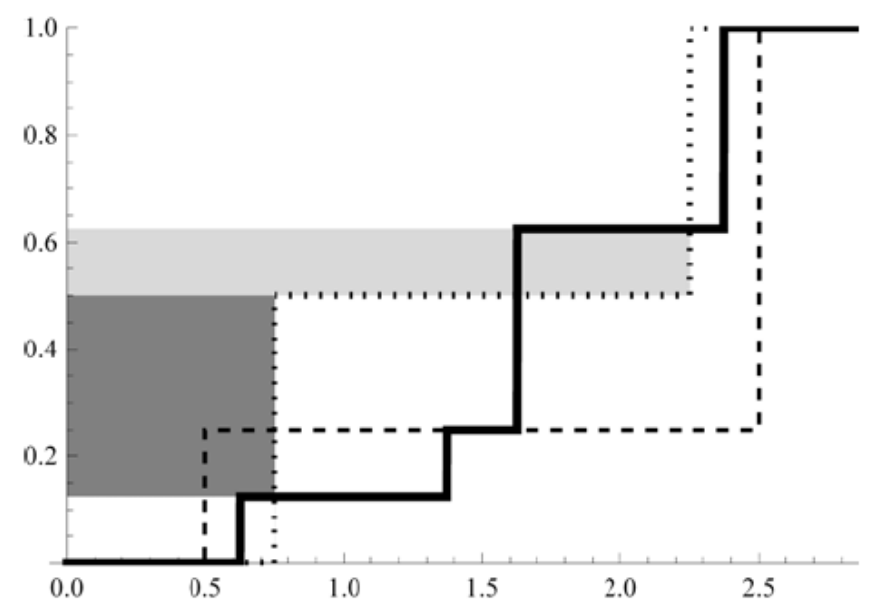

Figure 5. Heterogeneous Projects: The dotted and dashed lines depict the cumulative distribution of returns of two heterogeneous projects, whereas the thick line depicts the distribution of the average returns of these two projects. The three possible types of rates in joint financing correspond to the three flat parts of the thick line. Assuming that the second rate $\left(r_{m}^{\prime \prime}\right)$ is obtained, the reduction in expected bankruptcy costs obtained with joint rather than separate financing (coinsurance effect) is equal to the darker gray area whereas the increase in expected bankruptcy costs obtained with joint rather than separate financing (risk contamination effect) is equal to the darker gray area. The parameters used in the graph are $p_{1}=0.75, p_{2}=0.5, r_{L}^{1}=0.5, r_{L}^{2}=0.75$, $r_{H}^{1}=2.5, r_{H}^{2}=2.25$.

(b) If condition (5) is satisfied but (4) is not satisfied, the equilibrium rate is $r_{m}^{\prime \prime}$;

(c) If condition (6) only is satisfied, the equilibrium rate is $r_{m}^{\prime \prime \prime}$.

The dotted and dashed lines in Figure 5 depict the cumulative distribution of returns of two heterogeneous projects, whereas the thick line depicts the distribution of the average returns of the two projects. The three possible types of rates in Proposition 5 correspond to the three flat parts of the average distribution.

\section{B. Good and Bad Conglomeration}

We now turn to the question of whether the borrower should finance the projects jointly or separately when both financing regimes are feasible. As in the symmetric case, if a rate that avoids bankruptcy in both intermediate situations can be obtained (case [a] in Proposition 5), projects coinsure each other and should be financed jointly. If the firm can only obtain a 
rate that does not avoid bankruptcy in any of the intermediate situations (case [c]), projects should be financed separately because they drag each other down. If bankruptcy can only be avoided for the more favorable intermediate situation (case [b]), then both coinsurance and contamination effects are present at the same time. On the one hand, project 1 , when it yields a high return, saves project 2 when project 2 yields a low return; on the other hand, project 1, when it yields a low return, contaminates project 2 when project 2 yields a high return. The optimality of separate or joint financing depends on whether the gains from coinsurance dominate the losses from risk contamination.

PROPOSITION 6: When the borrower can finance two heterogeneous projects separately as well as jointly:

(a) If condition (4) is satisfied, it is optimal to finance the projects jointly to enjoy the coinsurance gains: $\left(1-p_{1}\right) p_{2}(1-\beta) r_{L}^{1}+p_{1}\left(1-p_{2}\right)(1-\beta) r_{L}^{2}$.

(b) If condition (5) is satisfied but (4) is not satisfied, it is optimal to finance the projects separately if and only if the risk contamination losses dominate the coinsurance gains: (1 $\left.p_{1}\right) p_{2}(1-\beta) r_{H}^{2}>p_{1}\left(1-p_{2}\right)(1-\beta) r_{L}^{2}$.

(c) If condition (6) only is satisfied, it is optimal to finance the projects separately to avoid the risk contamination losses: $p_{1}\left(1-p_{2}\right)(1-\beta) r_{H}^{1}+\left(1-p_{1}\right) p_{2}(1-\beta) r_{H}^{2}$.

In the new case (b), the probability of default with joint financing is (i) increased by $\left(1-p_{1}\right) p_{2}$, as a successful project 2 would be dragged down if project 1 failed, but (ii) decreased by $p_{1}\left(1-p_{2}\right)$, as a failing project 2 would be saved if project 1 was successful. Project 2, however, is saved when it yields a low return but it is dragged down following a high return. Thus if the two projects have the same probability of success, the risk contamination effect always dominates the coinsurance effect.

The tradeoff between coinsurance and risk contamination in the new case (b) is depicted in Figure 5. The risk-contamination losses, equal to $\left(1-p_{1}\right) p_{2}(1-\beta) r_{L}^{2}$, are represented by the light gray area and correspond to the added bankruptcy costs on the high-return project 2 that is dragged down when project 1 has a low return. The coinsurance gains, equal to $p_{1}\left(1-p_{2}\right)(1-\beta) r_{H}^{2}$, are represented by the gray area and correspond to reduced bankruptcy costs on the low-return project 2 that is saved when project 1 has a high return. For the numerical value used in the figure, it is more profitable to finance the projects separately because the risk-contamination losses are larger than the coinsurance gains.

When projects are heterogeneous, separation has the additional advantage of allowing 
for project-specific loans. We now characterize situations in which it is better to finance a high-expected return separately rather than jointly with a low-expected return project. In some cases, separate financing is optimal even if a rate that avoids bankruptcy for all intermediate returns can be obtained (condition (4) is satisfied).

Proposition 7: Suppose that project 1 first-order stochastically dominates project 2, and in particular, $r_{H}^{1}=r_{H}^{2}$ and $r_{L}^{1}=r_{L}^{2}=r_{L}$ and $p_{1}>p_{2}$, and only the high-mean project 1 can be financed separately. Then the borrower should only finance project 1 unless (i) condition (4) is satisfied and (ii) the ex post net present value of financing the low-mean project 2 separately is compensated by the coinsurance effects, i.e., if and only if $\left[\left(1-p_{2}\right) p_{1}+\left(1-p_{1}\right) p_{2}\right](1-$ $\beta) r_{L}>1-p_{2} r_{H}-\left(1-p_{2}\right) \beta r_{L}$.

\section{C. $\quad$ Testable Predictions}

For the case in which one project is a mean preserving spread of the other, the next result establishes that more risk typically induces more separation.

PREDICTION 5: If project 2 second-order stochastically dominates project 1 , and therefore $p_{1}=p_{2}$ and $r_{H}^{1}=r_{H}^{2}+\varepsilon$ and $r_{L}^{1}=r_{L}^{2}-\frac{p_{1}}{1-p_{1}} \varepsilon$ for $\varepsilon>0$, a higher spread of the risky project (higher $\varepsilon$ ) leads to a decrease in the region of parameters for which joint financing is optimal.

As explained after Proposition 6, if the probabilities of success are the same joint financing is optimal only if condition (4) is satisfied. This condition becomes more stringent as the spread of the risky project increases. Indeed, the less favorable intermediate returns $\left(r_{L}^{1}+r_{H}^{2}\right)$ decrease in the spread of project 1 and the repayment rate $\left(r_{m}^{\prime}\right)$ increases, as the creditor recovers less in the event of bankruptcy (when both projects yield low returns). In addition, it is easier to finance the projects separately as the increase in the high realization of the return is not compensated by the increase in the repayment rate $\left(r_{i}\right)$.

Gorton and Souleles (2005) and Bannier and Hansel (2008) provide evidence on which banks are more likely to use securitization, a form of separate financing especially designed to avoid bankruptcy procedures of separated assets. They show that riskier originator banks are more likely to securitize. This is consistent with our prediction, which claims that separation is more likely if the risky project (the bank) is riskier. Evidence on off-balance sheet debt is also consistent with this prediction as firms with greater credit risks are more likely to use off-balance sheet debt (Mills and Newberry (2005)). 
For the case in which two projects have different probabilities of success, the next result establishes that higher means typically induces less separation.

PREDICTION 6: If project 1 first-order stochastically dominates project 2, and in particular, $r_{H}^{1}=r_{H}^{2}$ and $r_{L}^{1}=r_{L}^{2}$ and $p_{1}>p_{2}$, for a higher mean of any of the two projects (higher $p_{1}$ or $p_{2}$ ), the region of parameters for which joint financing is optimal increases.

\section{Managerial Implications}

In Section II.F we showed that the option with the lowest repayment rate does not need to result in the lowest likelihood of bankruptcy and it is therefore not necessarily optimal. Here we show that the financing option with the lowest probability of bankruptcy might not be optimal either.

Proposition 8: Separate financing is optimal even though it results in a higher probability of bankruptcy if and only if ( $i$ ) condition (5) is satisfied and (4) is not satisfied, (ii) the riskcontamination losses dominates coinsurance gains: $\left(1-p_{1}\right) p_{2}(1-\beta) r_{H}^{2}>p_{1}\left(1-p_{2}\right)(1-\beta) r_{L}^{2}$, and (iii) the probability of risk contamination is lower than the probability of coinsurance: $p_{1}>p_{2}$.

As shown in Proposition 6, if condition (5) is satisfied, we have that (i) if project 1 yields a low return, it drags down project 2's high return (whereas project 2 would have stayed afloat with separate financing) and (ii) if project 1 yields a high return, it saves project 2's low return (whereas project 2 would have defaulted with separate financing). Projects should then be financed separately if the expected benefits from coinsuring the second project dominate the expected losses from risk-contaminating it. Even when the second project is more likely to be saved $\left(p_{1}>p_{2}\right.$ and therefore $\left.p_{1}\left(1-p_{2}\right)>p_{2}\left(1-p_{1}\right)\right)$, the risk contamination effect might still dominate because the potential losses from dragging down a successful project are higher than the potential gains from saving an unsuccessful one $\left(r_{H}^{2}>r_{L}^{2}\right)$. Therefore, separation is optimal even if it entails a higher probability of bankruptcy. Figure 5 is an example in point.

\section{Correlated Projects}

To allow for correlation, we now modify the distribution of joint returns for the baseline case with two identical projects. Suppose that the probability of two high returns result is 
equal to $p[1-(1-p)(1-\rho)]$, the probability of two low returns is equal to $(1-p)[1-p(1-\rho)]$, and the probability that one of the projects yields a high return whereas the other yields a low one is equal to $p(1-p)(1-\rho)$. Thus $\rho$ is the correlation coefficient between the two projects. For the joint probability distribution to be well defined, it is necessary to assume that $\rho \geq \max \langle-(1-p) / p,-p /(1-p)\rangle$. Clearly, if $\rho=0$ we are back to the baseline scenario with independent returns.

PREDiCTION 7: If the correlation between the projects increases ( $\rho$ is larger), then separate financing is optimal for a larger set of parameters.

The probability of having two high returns and the probability of having two low returns increase simultaneously with $\rho$. As a result, the repayment rate when intermediate bankruptcy is avoided is higher because the probability of two low returns is higher. When intermediate bankruptcy cannot be avoided, the repayment rate is lower because the probability of two high returns also increases. As a consequence, the financing conditions avoiding intermediate bankruptcy are tighter and those not avoiding it looser.

The effects of correlation on the optimality conditions are also intuitive. In the extreme case with perfect negatively correlation (i.e., if $\rho=-1$ and $p=1 / 2$ ), when one project has a high return the other necessarily has a low one, so that projects can always be jointly financed at a rate that avoids intermediate bankruptcy. ${ }^{13}$ Thus, it is clearly optimal to always finance projects jointly when the negative correlation is perfect. As correlation increases above $\rho=-1$, conglomeration is optimal for a smaller region of parameters. If projects have perfect positive correlation $(\rho=1)$, the conditions for joint and separate financing are identical and the firm is clearly indifferent between them. This prediction is similar to the one obtained by Inderst and Müller (2003) and by Leland (2007).

\section{Large Number of Projects}

Consider a borrower with access to a large number of identical projects with independent returns. We show that if the number of projects is sufficiently large, it always becomes possible for the borrower to finance all the projects with a single loan. This result exploits the law of large numbers. Namely, as the number of projects $n$ increases, the probability that the average number of projects with high returns differs from $p$, the probability of a

\footnotetext{
${ }^{13}$ This is not true for $p \neq 1 / 2$ because either the probability of two high realizations or the probability of two low realizations is greater than 0 , even when the correlation is at the lowest possible level.
} 
high return, by more than a small amount $\varepsilon$ tends to zero. We can then construct a rate offer to finance all projects jointly that is acceptable for the creditors. The borrower's returns when financing all projects jointly is then arbitrarily close to the first-best as the number of projects grows large. Therefore, for a large number of projects financing all the projects jointly is approximately optimal for the borrower because it yields a payoff that is close to the highest possible level.

Proposition 9: There exists $n^{\prime}$ and $q \in(0, p)$ such that when the number of projects satisfies $n>n^{\prime}$, joint financing of all projects can be obtained at a repayment rate that avoids bankruptcy when $n q$ projects have high returns. The resulting per-project return approaches the net present expected value of each project as $n$ grows.

This result leads to our next prediction:

Prediction 8: If there is a large number of independent projects, it is optimal to finance them jointly.

\section{Non-Proportional Bankruptcy Costs}

The analysis so far assumes that bankruptcy costs and recovery rates are proportional to the realized returns. That is, if the realized returns are given by $r$, the amount recovered by the creditor following bankruptcy is given by $R(r) \equiv \beta r$ for $\beta \in[0,1]$. This section considers the robustness of our results to different specification for bankruptcy costs. First, we show that if bankruptcy costs are incurred on a per-project basis, independently of the realized returns, separate financing then becomes optimal for an even larger set of parameters. Second, when instead there are economies of scale in bankruptcy costs, we show that the parameter region for which joint financing is optimal increases, as is natural to expect.

Proposition 10: Suppose that the bankruptcy costs are incurred on a per-project basis, independently of the level of returns, rather than on a proportional basis: per-project bankruptcy costs are equal to $b$, with $0<b<r_{L}$, which means that the recovered returns are $R(r) \equiv r-n_{j} b$, where $n_{j}$ is the number of projects. Then, separate financing is optimal for a larger set of parameters compared with the baseline of proportional bankruptcy costs.

If bankruptcy costs are incurred on a per-project basis rather than on a proportional basis, the proceeds from a bankrupt high-return project are relatively higher. As a result, 
the rate that does not avoid intermediate bankruptcy, $r_{m}^{* *}$, is reduced and condition (3) becomes easier to satisfy. Rates $r_{i}^{*}$ and $r_{m}^{*}$, instead, are the same as those resulting with proportional bankruptcy costs, so that conditions (1) and (2) do not change. As a result, it becomes easier to obtain joint financing, but only at the rate for which intermediate bankruptcy occurs. Therefore, when both separate and joint financing are feasible, separate financing is optimal for a larger set of parameters.

Proposition 11: Suppose that there are economies of scale in bankruptcy rather than constant returns to scale: recovered returns are equal to $R(r) \equiv \widehat{\beta}(r) r$, where $\widehat{\beta}(r) \in[0,1]$ is strictly increasing in $r$. Then, joint financing is optimal for a larger set of parameters compared with the baseline of proportional bankruptcy costs.

The introduction of economies of scale in bankruptcy increases the profitability of joint financing. Due to scale economies, the per-project bankruptcy costs of two projects that are financed jointly are relatively lower than the bankruptcy costs of a project that is financed separately. Suppose for example that the non-proportional bankruptcy costs at $r_{L}$ are the same as in the proportional case, i.e. $\widehat{\beta}\left(r_{L}\right)=\beta$. Then, the bankruptcy proceeds in (1) and $r_{i}^{*}$ are the same as in the proportional case whereas the bankruptcy proceeds in (2) and (3) are higher, so that both $r_{m}^{*}$ and $r_{m}^{* *}$ are now lower. Given that it becomes easier to satisfy condition (2), joint financing becomes optimal for a larger set of parameters when there are economies of scale in bankruptcy costs.

\section{Debt, Equity, and Taxes}

This section allows the firm to use equity, as well as debt, to finance part of the initial investment. As in the standard tradeoff theory of capital structure, equity payments are subject to corporate taxation, whereas debt payments are tax deductible and are therefore exempt from taxes.

\section{A. Model Extension}

Financing for each corporation can be obtained in competitive credit and equity markets. As in the basic model, the availability of a competitive credit market is equivalent to assuming that each corporation makes a take-it-or-leave-it offer to a single creditor. Corporation $j$, consisting of $n_{j}$ projects, promises to repay $n_{j} r_{j}^{\prime}$ at $t=2$ in exchange of $n_{j} D_{j}$ at $t=1$. Thus, 
the promised per-project repayment $r_{j}^{\prime}$ now depends on the part of the initial investment outlay of each project that is financed through debt, $D_{j} \leq 1$.

A competitive equity market is equivalent to assuming that each corporation makes a take-it-or-leave-it offer to a single outside equity investor. We denote the fraction of the equity sold by corporation $j$ as $\alpha_{j}$, and the equity value of the corporation, if it consists of $n_{j}$ projects, as $n_{j} E_{j}$. In order to finance all its projects, the sum of debt and equity financing per-project must cover the initial investment outlay of each project, $D_{j}+\alpha_{j} E_{j}=1$. We also assume that, while debt payments are tax deductible and therefore exempt from taxes, equity payments are subject to a corporate $\operatorname{tax}$ of $\tau$, which captures the tax penalty of equity relative to debt. ${ }^{14}$

As we argued in Section I, the debt contract is the optimal contractual arrangement between an investor and the corporation if returns are privately observed by the corporation and can only be verified by the investors only by inducing bankruptcy and incurring the bankruptcy costs. The equity and debt contracts we characterize in this section are also the optimal contracts under the assumption that equity investors observe returns directly without the need of incurring verification/bankruptcy costs, but are subject to higher taxation than debt, whereas debt investors can only observe the returns by inducing bankruptcy. Thus our interpretation of the model in terms of costly state verification remains valid also in the presence of tax-disadvantaged equity.

\section{B. Financing Conditions}

For the case of separate financing, we now need to distinguish two cases, because there are situations in which it is possible to obtain a rate $r_{i}^{\prime}$ that avoids bankruptcy altogether, $r_{i}^{\prime} \leq r_{L}$, by selling a fraction $\alpha$ of the corporation. If this rate exists, it should satisfy

$$
\alpha(1-\tau)\left[p\left(r_{H}-r_{i}^{\prime}\right)+(1-p)\left(r_{L}-r_{i}^{\prime}\right)\right]=\alpha E_{i} \text { and } r_{i}^{\prime}=D_{i} .
$$

\footnotetext{
${ }^{14}$ Leland (2007) makes the more realistic assumption that only interest expenses are tax deductible. This, however, creates an endogeneity problem. When interest only is deductible, the fraction of debt service attributed to interest payments depends on the value of the debt, which in turn depends on the fraction of debt service attributed to interest payments. Instead of relying in numerical techniques to find debt values and optimal leverage, we follow Kale, Noe, and Ramirez (1991) and assume that both interest and principle are tax deductible. We also assume away personal taxes.
} 
Since there is no bankruptcy, the net interest rate is zero and the principal is equal to the debt value. Substituting into the total financing condition, $D_{i}+\alpha E_{i}=1$, this rate can be obtained if and only if

$$
r_{i}^{\prime}(\alpha):=\frac{1-\alpha(1-\tau)\left[p r_{H}+(1-p) r_{L}\right]}{1-\alpha(1-\tau)} \leq r_{L} .
$$

If the firm uses no equity $(\alpha=0)$, then $r_{i}^{\prime}=1$ and the condition is never satisfied $\left(r_{L}<1\right)$, as in the baseline debt-only case. But, as more equity is offered, the debt repayment is lower $\left(r_{i}^{\prime}(\alpha)\right.$ is decreasing) and, if taxes are low, the condition can be satisfied. Equity, however, is costly because of taxes. It is optimal for the firm to sell the lowest equity stake $\alpha_{i}^{\prime}$ satisfying condition $(7), r_{i}^{\prime}\left(\alpha_{i}^{\prime}\right)=r_{L}$. Still, if taxes are high enough, it is not possible to obtain this rate, not even by selling all the equity.

Following the same procedure, a rate such that $r_{i}^{\prime \prime}<r_{H}$ can be obtained if and only if

$$
r_{i}^{\prime \prime}(\alpha):=\frac{1-\alpha(1-\tau) p r_{H}-(1-p) \beta r_{L}}{[1-\alpha(1-\tau)] p} \leq r_{H}
$$

which generalizes condition (1) of the baseline setup to $\alpha>0$, as $r_{i}^{\prime \prime}(0)=r_{i}^{*} \leq r_{H}$. This condition is satisfied precisely as long as condition (1) is satisfied, independently of the level of equity sold. Given that the firm prefers to sell the lowest possible fraction of equity, no equity at all is sold in the optimum, $\alpha_{i}^{\prime \prime}=0$. In this case, equity does not help to reduce the probability of bankruptcy.

The following proposition characterizes which of these two rates is optimally chosen when they are both available.

Proposition 12: Suppose that both rates $r_{i}^{\prime}$ and $r_{i}^{\prime \prime}$ are available. There exists $\bar{\tau}_{i}$ such that the optimal rate and fraction of equity sold are, respectively, $r_{L}$ and $\alpha_{i}^{\prime}>0$ if $\tau \leq \bar{\tau}_{i}$, and $r_{i}^{*}$ and $\alpha=0$ if $\tau>\bar{\tau}_{i}$.

If taxes are sufficiently high, the projects are financed at the same rate as in the baseline case without equity. Moreover, it is then optimal to finance the projects entirely with debt. When taxes are lower, however, it becomes optimal to finance the projects at a rate that avoids bankruptcy altogether $\left(r_{i}^{\prime}\left(\alpha_{i}^{\prime}\right)=r_{L}\right)$ by selling a positive amount of equity, $\alpha_{i}^{\prime}>0$.

For the case of joint financing, there are three potential rates. The first rate, which avoids bankruptcy altogether, $r_{m}^{\prime} \leq r_{L}$, is the same as (and can be obtain under the same circumstances as) the rate resulting with separate financing, $r_{m}^{\prime}=r_{i}^{\prime}$. Indeed, if bankruptcy can be avoided, then the corporate structure does not matter. 
Second, a rate that avoids bankruptcy if one realized return is high and the other is low can be obtained if and only if

$$
r_{m}^{\prime \prime}(\alpha):=\frac{1-\alpha(1-\tau)\left[p^{2} r_{H}+2 p(1-p) \frac{r_{H}+r_{L}}{2}\right]-(1-p)^{2} \beta r_{L}}{[1-\alpha(1-\tau)]\left[1-(1-p)^{2}\right]} \leq \frac{r_{H}+r_{L}}{2},
$$

which is again a generalization for $\alpha \geq 0$ of condition (2) of the baseline case, $r_{m}^{\prime \prime}(0)=r_{m}^{*} \leq$ $\left(r_{H}+r_{L}\right) / 2$. Again, it is optimal for the firm to choose the minimum amount of equity that satisfies condition (9). If condition (2) is satisfied, the firm does not need to sell any equity at all, $\alpha_{m}^{\prime \prime}=0$. If condition (2) is not satisfied, this rate can still be obtained, however, by selling some equity.

Third, a rate that avoids bankruptcy only if both realized returns are high can be obtained as long as

$$
r_{m}^{\prime \prime \prime}(\alpha):=\frac{1-(1-p)^{2} \beta r_{L}-2 p(1-p) \beta \frac{r_{H}+r_{L}}{2}-\alpha(1-\tau) p^{2} r_{H}}{[1-\alpha(1-\tau)] p^{2}} \leq r_{H},
$$

which again, generalizes the condition of the baseline case for $\alpha \geq 0$, i.e. $r_{m}^{\prime \prime \prime}(0)=r_{m}^{* *} \leq r_{H}$. As in the highest rate for separate financing, this condition is satisfied precisely as long as condition (3) is satisfied, independently of the equity sold. Given that the firm prefers to sell the lowest possible fraction of equity, the resulting level is $\alpha_{m}^{\prime \prime \prime}=0$.

Proposition 13: Suppose more than one rate $\left(r_{m}^{\prime}, r_{m}^{\prime \prime}, r_{m}^{\prime \prime \prime}\right)$ is available. There exist $\bar{\tau}_{m}^{a}$, $\bar{\tau}_{m}^{b}$, and $\bar{\tau}_{m}^{c}$ such that:

(i) If condition (2) is satisfied, the optimal rate and fraction of equity sold are, respectively, $r_{L}$ and $\alpha_{m}^{\prime}>0$ if $\tau \leq \bar{\tau}_{m}^{a}$, and $r_{m}^{*}$ and $\alpha=0$ if $\tau>\bar{\tau}_{m}^{a}$.

(ii) If condition (2) is not satisfied, the optimal rate and fraction of equity sold are, respectively, $r_{L}$ and $\alpha_{m}^{\prime}>0$ if $\tau \leq \bar{\tau}_{m}^{b}, \frac{r_{H}+r_{L}}{2}$ and $\alpha_{m}^{\prime \prime}>0$ if $\bar{\tau}_{m}^{b}<\tau \leq \bar{\tau}_{m}^{c}$, and $r_{m}^{* *}$ and $\alpha=0$ if $\tau>\bar{\tau}_{m}^{c}$

\section{Good and Bad Conglomeration}

The profitability of merging depends on the cases identified in Proposition 13. In case (i), merging is always profitable at least weakly. This case is equivalent to the case of good conglomeration in the baseline model. The condition is exactly the same as the condition enabling the firm to obtain $r_{m}^{*}$ in Section II. In case (ii), conglomeration is bad in the baseline model. And, if taxes are sufficiently high, conglomeration is still bad here. If taxes are lower, however, financing with equity allows the firm to finance the projects with rates 
that avoid bankruptcy in the case with intermediate returns and even altogether.

Proposition 14: When both separate and joint financing are feasible:

(i) If condition (2) is satisfied, both financing regimes are equally profitable if $\tau \leq \bar{\tau}_{m}^{a}$, whereas joint financing dominates if $\tau>\bar{\tau}_{m}^{a}$.

(ii) If condition (2) is not satisfied, both financing regimes are equally profitable if $\tau \leq \bar{\tau}_{m}^{b}$, joint financing dominates if $\bar{\tau}_{m}^{b}<\tau \leq \bar{\tau}_{i}$, and separate financing dominates if $\tau>\bar{\tau}_{i}$.

In sum, if taxes are sufficiently high, only debt is used and the same situation analyzed in the baseline model arises. That is, joint financing is profitable in case (i) and separate financing is profitable in case (ii). The condition setting apart joint and separate financing is exactly the same as in the baseline model without equity. If taxes are intermediate, joint financing can be profitable in cases in which it is not profitable in the baseline model with only debt (case ii). This is because, by financing jointly, it becomes possible to obtain a rate that avoids intermediate bankruptcy or bankruptcy altogether by using equity. Finally, if taxes are sufficiently low, joint financing is inconsequential because bankruptcy can be avoided altogether with joint as well as with separate financing.

The exclusive use of debt in separate finance is consistent with the many empirical studies that find that a disproportionate proportion of funding in project finance is in the form of debt. Kleimeier and Megginson (2000), for example, find that projects funded with project finance loans have an average loan-to-project value ratio of $67 \%$. Esty (2003) shows that the average (respectively median) project company has a book value debt-to-total capitalization ratio of $70 \%$ (respectively $70 \%$ ) compared to $33.1 \%$ (respectively $30.5 \%$ ) for similar-sized firms.

\section{Conclusion}

This paper analyzes the simple economics of conglomeration with bankruptcy costs. Our results qualify the long-standing claim that joint financing generates financial benefits by economizing on bankruptcy costs. By turning on its head the classic logic that generates coinsurance savings from conglomeration, we characterize instances in which expected bankruptcy costs increase because of risk contamination.

We provide a full and intuitive characterization of the tradeoff between coinsurance and risk contamination when projects have binary returns. The main predictions we obtain are the following: 
- An increase in the bankruptcy recover rate and an increase in the probability of a high return favor joint financing;

- An increase in the riskiness of (sufficiently negatively skewed) projects favors separate financing;

- An increase in the negative skewness of projects (with sufficiently high return) favors separate financing;

- An increase in the differences in terms of risk profiles of two heterogeneous projects favors separate financing;

- An increase in the correlation of projects favors separate financing;

- Joint financing of a sufficiently large number of independent projects is optimal.

In addition, we show that separate financing can be optimal even when joint financing involves paying a lower repayment rate or results in a lower probability of bankruptcy.

We conclude by discussing a number of extensions of the model. In our setup, investors in both projects have recourse to the returns of the other project (with joint financing) or none of them have access to the returns of the other (with separate financing). In reality, an asymmetric, intermediate situation could also arise whereby investors in one (recourse) project have access to the returns of the other (nonrecourse) project, but not conversely. In this case, one of the diagonal entries in Figure 1 would be like the case of separate financing. That is, if the project with nonrecourse has a low return and the one with recourse has a high return, the former would go bankrupt and the latter would stay afloat. In the other diagonal entry, however, both projects would stay afloat if the recourse project can be saved by the nonrecourse one. If so, the intermediate solution would be better than separate financing but if not, it would be worse. A complete analysis for the resulting tradeoff is left to future research.

Saving an unsuccessful project might sometimes be optimal for reputational reasons, even if it has been financed with (nonrecourse) debt and the firm is under no legal obligation to save it. Gorton (2008), for example, points out that securitization issuers retain substantial implicit exposure even after mortgages are securitized. In the credit card asset-based securities (ABS) market, for example, Higgins and Mason (2004) document instances in which issuers of credit card ABS have taken back non-performing loans despite not being contractually required to do so. Similarly, Gorton and Souleles (2006) show that prices paid 
by investors in credit card ABS take into account issuers' ability to bail out their ABS. To capture this tradeoff, one could extend our static model to a dynamic framework.

It is also natural to extend the model to allow for multiple (and possibly risk-averse) investors. This extension could build on Winton's (1995) result that debt-like contracts with varying seniority arise as optimal financial arrangements to economize on the duplication of verification costs that are spent by the multiple investors. In this vein, Bond (2004) analyzes the optimal architecture of intermediation when intermediaries are also subject to verification costs, as in Diamond (1984).

From a theoretical perspective, the problem of project bundling analyzed here is closely connected to the problem of pure product bundling that has been analyzed extensively in the industrial organization literature (see Adams and Yellen (1976), Armstrong (1999), and Fang and Norman (2006)). So far the literatures on project and product bundling have developed in parallel, but departing from opposite premises. For the problem of product bundling, the naive intuition prevailing before Adams and Yellen's (1976) seminal contribution favored product separation; hence Adams and Yellen (1976) stressed the somewhat counterintuitive advantages of bundling products. For the problem of project bundling, instead, the initial view found the advantages of project bundling more intuitive (Lewellen (1971)); hence we stress the advantages of separation. In reality, the decision of whether to bundle or separate is driven by similar forces in the two problems of product pricing and project financing. As we argue in Supplementary Appendix B, the reduction in the dispersion of returns induced by project bundling is similar to the reduction in the dispersion of buyers' willingness to pay induced by product bundling. Further development of this connection is a promising area for future research. 


\section{Appendix A \\ Proofs}

Proof of Proposition 1: The proof follows from the analysis reported in the text.

Q.E.D.

Proof of Proposition 2: If projects can be financed separately, i.e. condition (1) is satisfied, the entrepreneur obtains a per-project return of $p\left(r_{H}-r_{i}^{*}\right)$, which is equal to the ex post net present value

$$
p r_{H}+\beta(1-p) r_{L}-1
$$

Similarly, if condition (2) is satisfied, the entrepreneur obtains a per-project return of $p^{2}\left(r_{H}-\right.$ $\left.r_{m}^{*}\right)+2 p(1-p)\left[\left(r_{H}+r_{L}\right) / 2-r_{m}^{*}\right]$, or

$$
p^{2} r_{H}+2 p(1-p)\left(r_{H}+r_{L}\right) / 2+\beta(1-p)^{2} r_{L}-1,
$$

and, if condition (3) but (2) is not satisfied, she obtains $p^{2}\left(r_{H}-r_{m}^{* *}\right)$, or

$$
p^{2} r_{H}+\beta 2 p(1-p)\left(r_{H}+r_{L}\right) / 2+\beta(1-p)^{2} r_{L}-1 .
$$

Subtracting (A2) from (A1), we obtain $(1-\beta) p(1-p) r_{L}$ and therefore joint financing is more profitable than separate financing. Instead, subtracting (A1) from (A2), we obtain $(1-\beta)(1-p) p r_{H}$ and therefore separate financing is more profitable than joint financing. Q.E.D.

Proof of Prediction 1: The statements follow from the fact that the derivatives of the lefthand of (1), (2), and (3) with respect to $\beta$ are negative. $\quad$ Q.E.D.

Proof of Prediction 2: The statements follow from the fact that the derivatives of the lefthand of (1), (2), and (3) with respect to $p$ are negative. $\quad$ Q.E.D.

Proof of Prediction 3: Letting $\varepsilon$ be such that $\widehat{r}_{H}=r_{H}+\varepsilon$, we have that, in order to have a mean preserving spread, $\widehat{r}_{L}=r_{L}-\frac{p}{1-p} \varepsilon$. Substituting into condition (2), the derivative of the left hand side less the derivative of the right hand side is equal to

$$
\frac{1-p}{2-p} \beta+\frac{1}{2(1-p)}-1
$$

which is positive if and only if $p>\bar{p}$, where $\bar{p} \equiv[1+4(1-\beta)-\sqrt{1+8(1-\beta)}] / 2(1-\beta)$. Therefore, condition (2) is less likely to be satisfied following an increase in $\varepsilon$ if and only if $p>\bar{p}$. It can be easily checked that $\bar{p}<1 / 2$ for any $\beta$. Q.E.D. 
Proof of Prediction 4: Letting $\varepsilon$ be such that $\widehat{r}_{L}=r_{L}-\varepsilon$, we have that, in order to have a mean preserving spread, $\widehat{p}=p-\frac{(1-p) \varepsilon}{r_{H}-r_{L}+\varepsilon}$. Following the same procedure as in the proof of the previous prediction, there exists $\bar{r}_{H}$, such that condition (2) is less likely to be satisfied following an increase in $\varepsilon$ if and only if $r>\bar{r}_{H}$. Q.E.D.

Proof of Proposition 3: (i) Suppose that $\beta$ and $r_{L}$ are arbitrarily close to 1, condition (2) is arbitrarily close to $\frac{r_{H}+r_{L}}{2}>1$ whereas condition (1) simplifies to $r_{H}>1$. Clearly there are situations in which condition (2) is satisfied, and therefore projects can be financed jointly, but condition (1) is not satisfied, and therefore projects cannot be financed separately.

(ii) If condition (2) is not satisfied, projects can only be financed jointly if condition (3) is satisfied. Condition (3) can be rewritten as

$$
p r_{H}-p(1-p) r_{H}(1-\beta)+(1-p) \beta r_{L}>1
$$

This implies that $p r_{H}+(1-p) \beta r_{L}>1$, which implies that projects can be financed separately. Of course, the opposite is not true, if the parameters are such that $p r_{H}+(1-p) \beta r_{L}$ is arbitrarily close to 1 , then condition (3) is not satisfied. Q.E.D.

Proof of Proposition 4: Suppose first that a rate below the crossing point can be obtained. We have that

$$
r_{m}^{*}=\frac{1-(1-p)^{2} \beta r_{L}}{1-(1-p)^{2}}<\frac{1-(1-p) \beta r_{L}}{p}=r_{i}^{*},
$$

because $1>\beta r_{L}$. Next, suppose that only a rate $r_{m}^{* *}$ above the crossing point can be obtained and therefore the probability of bankruptcy is higher with joint financing. Nevertheless, the rate $r_{m}^{*}$ associated with joint financing is lower than $r_{i}^{*}$ associated with separate financing whenever

$$
r_{m}^{* *}=\frac{1-(1-p) \beta\left(p r_{H}+r_{L}\right)}{p^{2}}<\frac{1-(1-p) \beta r_{L}}{p}=r_{i}^{*},
$$

or equivalently when

$$
\beta r_{H}>\frac{1-(1-p) \beta r_{L}}{p}=r_{i}^{*}
$$

as claimed. Q.E.D.

Proof of Proposition 5: Following the same procedure as in the symmetric case, the repayment rate should satisfy $1<r_{i}^{\prime}<r_{H}^{i}$. The creditor's zero profit condition is now

$$
\operatorname{pr}_{i}^{\prime}+\left(1-p_{i}\right) \beta r_{L}^{i}-1=0
$$


and project $i$ can be financed (at $r_{i}^{\prime}$ ) if and only if

$$
r_{i}^{\prime}:=\frac{1-\left(1-p_{i}\right) \beta r_{L}^{i}}{p_{i}}<r_{H}^{i}
$$

There are three cases in which joint financing is feasible depending on whether bankruptcy can be avoided in both cases with intermediate returns, or only when project 1 yields a high return and project 2 yields a low return, or in neither case. In the former case, competitive credit markets imply that

$$
\left[1-\left(1-p_{1}\right)\left(1-p_{2}\right)\right] 2 r_{m}^{\prime}+\left(1-p_{1}\right)\left(1-p_{2}\right) \beta\left(r_{L}^{1}+r_{L}^{2}\right)-2=0
$$

and therefore this is possible if and only if

$$
r_{m}^{\prime}:=\frac{1-\left(1-p_{1}\right)\left(1-p_{2}\right) \beta \frac{r_{L}^{1}+r_{L}^{2}}{2}}{1-\left(1-p_{1}\right)\left(1-p_{2}\right)}<\frac{r_{L}^{1}+r_{H}^{2}}{2} .
$$

If default can be avoided with high intermediate returns but not with low intermediate returns, then

$$
p_{1} p_{2} 2 r_{m}^{\prime \prime}+p_{1}\left(1-p_{2}\right) 2 r_{m}^{\prime \prime}+\left(1-p_{1}\right) p_{2} \beta\left(r_{L}^{1}+r_{H}^{2}\right)+\left(1-p_{1}\right)\left(1-p_{2}\right) \beta\left(r_{L}^{1}+r_{L}^{2}\right)-2=0,
$$

and therefore this is possible if and only if

$$
\frac{r_{L}^{1}+r_{H}^{2}}{2}<r_{m}^{\prime \prime}:=\frac{1-\left(1-p_{1}\right) p_{2} \beta \frac{r_{L}^{1}+r_{H}^{2}}{2}-\left(1-p_{1}\right)\left(1-p_{2}\right) \beta \frac{r_{L}^{1}+r_{L}^{2}}{2}}{p_{1}}<\frac{r_{H}^{1}+r_{L}^{2}}{2} .
$$

If default cannot be avoided with either intermediate returns, then

$$
p_{1} p_{2} 2 r_{m}^{\prime \prime \prime}+p_{1}\left(1-p_{2}\right) \beta\left(r_{H}^{1}+r_{L}^{2}\right)+\left(1-p_{1}\right) p_{2} \beta\left(r_{L}^{1}+r_{H}^{2}\right)+\left(1-p_{1}\right)\left(1-p_{2}\right) \beta\left(r_{L}^{1}+r_{L}^{2}\right)-2=0
$$

and therefore this is possible if and only if

$$
\frac{r_{H}^{1}+r_{L}^{2}}{2}<r_{m}^{\prime \prime \prime}<\frac{r_{H}^{1}+r_{H}^{2}}{2}
$$

where

$$
r_{m}^{\prime \prime \prime}:=\frac{1-p_{1}\left(1-p_{2}\right) \beta \frac{r_{H}^{1}+r_{L}^{2}}{2}-p_{2}\left(1-p_{1}\right) \beta \frac{r_{L}^{1}+r_{H}^{2}}{2}-\left(1-p_{1}\right)\left(1-p_{2}\right) \beta \frac{r_{L}^{1}+r_{L}^{2}}{2}}{p_{1} p_{2}} .
$$

Again, since the borrower obtains all the ex post net present value, rate $r_{m}^{\prime}$ is preferred to $r_{m}^{\prime \prime}$ and $r_{m}^{\prime \prime}$ is preferred to $r_{m}^{\prime \prime \prime}$. To complete the proof we only need to show that the lower bound conditions for $r_{m}^{\prime \prime}$ and $r_{m}^{\prime \prime \prime}$ are irrelevant. From (A6) and (A8), and rearranging, we 
have

$$
p_{1}\left(r_{m}^{\prime}-r_{m}^{\prime \prime}\right)=p_{2}\left(1-p_{1}\right)\left[\beta\left(\frac{r_{L}^{1}+r_{H}^{2}}{2}\right)-r_{m}^{\prime}\right],
$$

and therefore if $r_{m}^{\prime}>\frac{r_{L}^{1}+r_{H}^{2}}{2}$ then the right hand side is negative. As a consequence, we have $r_{m}^{\prime \prime}>r_{m}^{\prime}>\frac{r_{L}^{1}+r_{H}^{2}}{2}$. Similarly, from (A8) and (A9) and rearranging, we have

$$
p_{2}\left(r_{m}^{\prime \prime}-r_{m}^{\prime \prime \prime}\right)=\left(1-p_{2}\right)\left[\beta\left(\frac{r_{H}^{1}+r_{L}^{2}}{2}\right)-r_{m}^{\prime \prime}\right]
$$

and therefore if $r_{m}^{\prime \prime}>\frac{r_{H}^{1}+r_{L}^{2}}{2}$ then the right hand side is negative. As a consequence, we have $r_{m}^{\prime \prime \prime}>r_{m}^{\prime \prime}>\frac{r_{H}^{1}+r_{L}^{2}}{2}$. Q.E.D.

Proof of Proposition 6: Substituting $r_{m}^{\prime}$ in the right hand side of (A6) and $r_{i}^{\prime}$ in the right hand side of (A4) and subtracting the latter from the former, we have

$$
p_{2}\left(1-p_{1}\right)(1-\beta) r_{L}^{1}+p_{1}\left(1-p_{2}\right)(1-\beta) r_{L}^{2}(>0) \text {. }
$$

Similarly, substituting $r_{m}^{\prime \prime}$ in the right hand side of (A8) and subtracting again the ex post net present value of financing the two projects separately from this, we obtain

$$
-\left(1-p_{1}\right) p_{2}(1-\beta) r_{H}^{2}+p_{1}\left(1-p_{2}\right)(1-\beta) r_{L}^{2}
$$

which can be positive or negative. Lastly, substituting $r_{m}^{\prime \prime \prime}$ in the right-hand side of (A9) and subtracting the ex post net present value of financing the two projects separately from this, we have

$$
-p_{1}\left(1-p_{2}\right)(1-\beta) r_{H}^{1}-p_{2}\left(1-p_{1}\right)(1-\beta) r_{H}^{2}(<0)
$$

as desired. Q.E.D.

Proof of Proposition 7: If only one project can be financed separately, we have that $p_{i} r_{H}+$ $\left(1-p_{i}\right) \beta r_{L}>1$ and $p_{j} r_{H}+\left(1-p_{j}\right) \beta r_{L}<1$ for $i \neq j$, where we denote again $r_{H}:=r_{H}^{i}$ and $r_{L}:=r_{L}^{i}$ for $i=1,2$. Then the expected surplus from funding the project separately is $p_{i} r_{H}^{i}+\left(1-p_{i}\right) \beta r_{L}^{i}-1$. Subtracting this from the expected surplus from joint financing in the case in which the repayment rate $r_{m}^{\prime}$ can be obtained and simplifying, we have

$$
p_{j} r_{H}+\left(1-p_{j}\right) \beta r_{L}-1+\left[\left(1-p_{j}\right) p_{i}+\left(1-p_{i}\right) p_{j}\right](1-\beta) r_{L}
$$

On the other hand, if we subtract this from the expected surplus from joint financing in the 
case in which the repayment rate $r_{m}^{\prime}$ can be obtained and simplifying, we obtain

$$
p_{j} r_{H}+\left(1-p_{j}\right) \beta r_{L}-1-\left[\left(1-p_{j}\right) p_{i}+\left(1-p_{i}\right) p_{j}\right](1-\beta) r_{H},
$$

so that separate financing is optimal because both terms are negative. Q.E.D.

Proof of Prediction 5: Given that one project is obtained from an elementary increase in risk from the other and returns should still be binary, we must have that $p_{1}=p_{2} \equiv p$. Letting $\varepsilon$ be such that $r_{H}^{1}=r_{H}^{2}+\varepsilon$, we have $r_{L}^{1}=r_{L}^{2}-\frac{p}{1-p} \varepsilon$. Indeed, $p\left(r_{H}^{2}+\varepsilon\right)+(1-p) r_{L}^{1}=p r_{H}^{2}+(1-p) r_{L}^{2}$. We can also check that $r_{L}^{1}+r_{H}^{2}=r_{L}^{2}-\frac{p}{1-p} \varepsilon+r_{H}^{2}<r_{L}^{2}+\varepsilon+r_{H}^{2}=r_{H}^{1}+r_{L}^{2}$.

As shown in the previous proposition, given that the probabilities of success are equal, we have that, when both projects can be financed separately as well as jointly, joint financing is only optimal if a rate $r_{m}^{\prime}$ can be obtained. Moreover, the region for which joint financing is optimal shrinks as the repayment rate $r_{m}^{\prime}$ is more difficult to obtain if $\varepsilon$ increases. Indeed, the left-hand side of condition (A7) decreases in $\varepsilon$ and the repayment rate (the right-hand side) increases in $\varepsilon$.

On the other hand, the region for which separate financing is possible expands if $\varepsilon$ increases. Indeed, the derivative of the left-hand side of condition (A5) is equal to $\beta$ whereas the right hand-side is equal to 1 . Hence, this condition is more easily satisfied as $\varepsilon$ increases. Q.E.D.

Proof of Prediction 6: From the proof of Proposition 5, if $r_{L}^{1}=r_{L}^{2}$ and $r_{L}^{1}=r_{L}^{2}$, we have that, when both projects can be financed separately as well as jointly, joint financing is only optimal if a rate $r_{m}^{\prime}$ can be obtained. The statement follows from the fact that the derivatives of the left-hand of (A7) with respect to $p_{1}$ and $p_{2}$ are negative. Q.E.D.

Proof of Proposition 8: Clearly, from Proposition 6, if statements (i) and (ii) are satisfied, separation is optimal. The probability of default of project 1 is the same in both financing regimes. With separate financing, the probability of default of project 2 is (i) reduced by $\left(1-p_{1}\right) p_{2}$, as a successful project 2 would not be dragged down if project 1 fails, but (ii) increased by $p_{1}\left(1-p_{2}\right)$, as a failing project 2 would not be saved if project 1 is successful. Given that, according to (iii), $p_{1}>p_{2}$, we have that $p_{1}\left(1-p_{2}\right)>\left(1-p_{1}\right) p_{2}$. As a result, the probability of default with separate financing is higher. Q.E.D.

Proof of Prediction 7: Clearly, separate financing is not affected by correlation. The joint financing repayment rates, $r_{m}^{*}$ and $r_{m}^{* *}$ in Proposition 1, and the corresponding financing 
conditions, are now replaced by $r_{m, \rho}^{*}$ and $r_{m, \rho}^{* *}$, respectively, where

$$
r_{m, \rho}^{*}:=\frac{1-(1-p)[1-p(1-\rho)] \beta r_{L}}{1-(1-p)[1-p(1-\rho)]}<\frac{r_{H}+r_{L}}{2},
$$

and

$$
r_{m, \rho}^{* *}:=\frac{1-(1-p) \beta r_{L}}{p[1-(1-p)(1-\rho)(1-\beta)]}<r_{H} .
$$

Note that $r_{m, \rho}^{*}$ and $r_{m, \rho}^{* *}$ are respectively increasing and decreasing in $\rho$. Q.E.D.

Proof of Proposition 9: First statement. Define $g(\gamma):=\gamma r_{H}+(1-\gamma) r_{L}$. We have that $g(p)>1$ because of the positive net present value condition, and trivially $g(0)=r_{L}<1$ and $g^{\prime}(\gamma)>0$. Then there exists a unique $\gamma^{*} \in(0, p)$ such that $g\left(\gamma^{*}\right)=1$. For a fixed rational number $\varepsilon$ (small) define $q:=\gamma^{*}+\varepsilon$. Clearly, $q r_{H}+(1-q) r_{L}>1$

Take any number of projects $n$ such that $n q$ is an integer number. Suppose that we were to finance all these $n$ projects jointly at an interest rate that avoids bankruptcy when at least $n q$ of them have high returns. This is possible if and only if the per-project repayment satisfies

$$
r_{n}^{*} \leq q r_{H}+(1-q) r_{L}
$$

But, the creditor's zero profit condition implies that

$$
r_{n}^{*}:=\frac{1-\beta\left(\sum_{k=0}^{n q-1} f(k) \frac{k r_{H}+(n-k) r_{L}}{n}\right)}{1-F(n q-1)},
$$

where $f(m)$ and $F(m)$ are the probability density and distribution that $m$ out of the $n$ projects have high returns, i.e.,

$$
f(m):=\left(\begin{array}{c}
n \\
m
\end{array}\right) p^{m}(1-p)^{n-m} \text { and } F(m):=\sum_{k=0}^{m} f(k) .
$$

Given that the returns recovered in the event of bankruptcy are positive we have that

$$
r_{n}^{*} \leq \frac{1}{1-F(n q-1)}<\frac{1}{1-F(n q)} .
$$

From the law of large numbers we have that $F(n q)$ tends to 0 as $n$ grows large (remembering that $q<p)$. Therefore $r_{n}^{*}$ is bounded above by a number that is arbitrarily close to 1 . Given that $q r_{H}+(1-q) r_{L}>1$, there exists $n^{\prime}$ such that for all $n>n^{\prime}$ then $r_{n}^{*}$ is such that

$$
r_{n}^{*} \leq q r_{H}+(1-q) r_{L}
$$

as was to be shown. 
Second statement: From the loan described above, the borrower obtains a per-project gross profit

$$
\pi_{n}=\beta \sum_{k=0}^{n q-1} f(k)\left[\frac{k}{n} r_{H}+\left(1-\frac{k}{n}\right) r_{L}\right]+\sum_{k=n q}^{n} f(k)\left[\frac{k}{n} r_{H}+\left(1-\frac{k}{n}\right) r_{L}\right] .
$$

Fix a small rational number $\varepsilon$ and an integer $n$ such that $n(p-\varepsilon)$ and $n(p+\varepsilon)$ are integer numbers. Then, given that $q<p-\varepsilon$, and that all terms in the first and in the second sum are positive, we have that

$$
\pi_{n} \geq \sum_{k=n(p-\varepsilon)}^{n(p+\varepsilon)} f(k)\left[\frac{k}{n} r_{H}+\left(1-\frac{k}{n}\right) r_{L}\right] .
$$

Given that the terms in the second factor in the sum are larger for larger $k$, the sum is reduced by replacing the summand of a given $k$ by that of $n(p-\varepsilon)$, the smallest term. Then, rearranging, we obtain

$$
\pi_{n} \geq\left[(p-\varepsilon) r_{H}+[1-(p-\varepsilon)] r_{L}\right][F[n(p+\varepsilon)]-F[n(p-\varepsilon)]]
$$

From the law of large numbers, $F[n(p+\varepsilon)]-F[n(p-\varepsilon)]$ tends to 1 as $n$ grows. Indeed from Chebyshev's inequality we know that

$$
F[n(p+\varepsilon)]-F[n(p-\varepsilon)] \geq 1-\frac{(p+\varepsilon)(1-p)}{n \varepsilon^{2}}-\frac{(1-p+\varepsilon) p}{n \varepsilon^{2}}=1-\frac{2 p(1-p)+\varepsilon}{n \varepsilon^{2}}
$$

and therefore

$$
\pi_{n} \geq\left[p r_{H}+(1-p) r_{L}-\varepsilon\left(r_{H}-r_{L}\right)\right]\left(1-\frac{2 p(1-p)+\varepsilon}{n \varepsilon^{2}}\right) .
$$

That is for $n$ large, the gross per-project profit differs from the (gross) present value of each project by an amount that is arbitrarily small, $\varepsilon\left(r_{H}-r_{L}\right)$. Similarly,

$$
\frac{\pi_{n}}{\pi^{*}} \geq\left(1-\frac{\varepsilon\left(r_{H}-r_{L}\right)}{p r_{H}+(1-p) r_{L}}\right)\left(1-\frac{2 p(1-p)+\varepsilon}{n \varepsilon^{2}}\right)
$$

where $\pi^{*}$ is equal to first-best gross profits, $\pi^{*}=p r_{H}+(1-p) r_{L}$. Q.E.D.

Proof of Prediction 8: The proof follows directly from Proposition 9. Q.E.D.

Proof of Proposition 10: The bankruptcy proceeds in (1), (2), and (3) (second term of the numerator of the left-hand side) become respectively $(1-p)\left(r_{L}-b\right),(1-p)^{2}\left(r_{L}-b\right)$, and $(1-p)\left(p\left(r_{H}-b\right)+r_{L}-b\right)$, instead of $\beta(1-p) r_{L}, \beta(1-p)^{2} r_{L}$, and $\beta(1-p)\left(p r_{H}+r_{L}\right)$.

If per-project bankruptcy costs are set at the same level as the fractional losses of the lowreturn project, $b=(1-\beta) r_{L}, r_{i}^{*}$, and $r_{m}^{*}$ are the same as those resulting from proportional bankruptcy costs, so that conditions (1) and (2) do not change. However, the rate $r_{m}^{* *}$ is 
now lower. Thus it becomes easier to satisfy condition (3) because the expected bankruptcy proceeds are now higher: $p\left(r_{H}-b\right)+r_{L}-b>\beta\left(p r_{H}+r_{L}\right)$. As a result, it becomes easier to obtain joint financing, but only at the rate for which intermediate bankruptcy occurs. Therefore, when both separate and joint financing are feasible, separate financing is optimal for a larger set of parameters. Q.E.D.

Proof of Proposition 11: The bankruptcy proceeds in (1), (2), and (3) (second term of the numerator of the left-hand side) become respectively $\widehat{\beta}\left(r_{L}\right)(1-p) r_{L}, \widehat{\beta}\left(2 r_{L}\right)(1-p)^{2}$, and $\widehat{\beta}\left(r_{H}+r_{L}\right) p(1-p)\left(r_{H}+r_{L}\right)+\widehat{\beta}\left(2 r_{L}\right)(1-p)^{2} r_{L}$, instead of $\beta(1-p) r_{L}, \beta(1-p)^{2} r_{L}$, and $\beta(1-p)\left(p r_{H}+r_{L}\right)$.

If the increasing bankruptcy costs at the low-return are set at the same level as the fractional losses, $\widehat{\beta}\left(r_{L}\right)=\beta$, then $r_{i}^{*}$ is the same as that resulting with proportional bankruptcy costs, so that condition (1) does not change. Rates $r_{m}^{*}$ and $r_{m}^{* *}$, on the other hand, are lower and conditions (2) and (3) are easier to satisfy, as $\widehat{\beta}\left(r_{H}+r_{L}\right)>\beta\left(r_{H}+r_{L}\right)$ and $\widehat{\beta}\left(2 r_{L}\right)>\beta 2 r_{L}$. Given that it becomes easier to satisfy condition (2), joint financing becomes optimal for a larger set of parameters when there are economies of scale in bankruptcy costs. Q.E.D.

Proof of Proposition 12: We proceed by computing the payoff obtained when using each of the two rates and then we compare the payoffs. If the firm uses $r_{i}^{\prime}(\alpha)$ (specified in $\left.(7)\right)$, the firm obtains, substituting into $(1-\alpha) E_{i}$,

$$
\frac{(1-\alpha)(1-\tau)}{\tau+(1-\alpha)(1-\tau)}\left[p r_{H}+(1-p) r_{L}-1\right] \text {. }
$$

This payoff is decreasing in $\alpha$, as the firm obtains a fraction of the net present value that corresponds to the (after-tax) equity holding; the remaining part is retained by the government through taxes. Therefore the firm should use the smallest level of equity possible. But, as explained in the text, the firm should use a positive level of equity to satisfy condition (7). Optimally, we have

$$
\alpha_{i}^{\prime}:=\frac{\left(1-r_{L}\right)}{(1-\tau)\left[p r_{H}+(1-p) r_{L}-1+\left(1-r_{L}\right)\right]} .
$$

Provided that $\alpha_{i}^{\prime} \leq 1\left(r_{i}^{\prime}(\alpha)\right.$ can be obtained), the firm obtains, substituting into (A11),

$$
\left[p r_{H}+(1-p) r_{L}-1\right]-\tau p\left(r_{H}-r_{L}\right)
$$

As argued in the text, if the firm uses $r_{i}^{\prime \prime}(\alpha)$ (specified in (8)), the optimal amount of 
equity is $\alpha_{i}^{\prime \prime}=0$. The borrower then obtains

$$
(1-\tau)\left[p r_{H}+(1-p) \beta r_{L}-1\right]
$$

Comparing the payoffs in each case, (A12) and (A13), it is optimal for the firm to choose the first over the second rate if and only

$$
\tau<\bar{\tau}_{i}:=1-\frac{\left(1-r_{L}\right)}{(1-\beta)(1-p) r_{L}+\left(1-r_{L}\right)},
$$

that is if bankruptcy costs $(1-\beta)$ are high enough and/or taxes are small. Q.E.D.

Proof of Proposition 13: Following the same procedure as in the proof of Proposition 12, we first compute the per-project payoff of the firm when using each of the three types of rate and then we compare these payoffs. If the projects are financed at a rate that avoids bankruptcy altogether, $r_{m}^{\prime}(\alpha)$, which is equal to $r_{i}^{\prime}(\alpha)$ (specified in $(7)$ ), the firm gets the same payoff as in the case of separate financing, i.e. equal to (A12). As in the case of separate financing, the firm needs to use a positive level of equity to obtain this rate, and therefore uses the minimum amount $\alpha_{m}^{\prime}>0$ such that $r_{m}^{\prime}\left(\alpha_{m}^{\prime}\right)=r_{L}$.

If projects are financed at a rate $r_{m}^{\prime \prime}(\alpha)$ (specified in (9)), the firm obtains

$$
(1-\tau)\left[p^{2} r_{H}+2 p(1-p)\left(\frac{r_{H}+r_{L}}{2}\right)+(1-p)^{2} \beta r_{L}-1\right]
$$

if condition (2) is satisfied and

$$
(1-\tau)\left[p^{2} r_{H}-p^{2} \frac{r_{H}+r_{L}}{2}\right]+\left[1-(1-p)^{2}\right] \frac{r_{H}+r_{L}}{2}+(1-p)^{2} \beta r_{L}-1
$$

if condition (2) is not satisfied. If condition (2) is satisfied, the firm does not need to use any equity to obtain $r_{m}^{\prime \prime}$, and therefore $\alpha_{m}^{\prime \prime}=0$ and $r_{m}^{\prime \prime}(0)=r_{m}^{*}$. If condition (2) is not satisfied, the firm needs to use a positive level of equity to obtain $r_{m}^{\prime \prime}$, and therefore uses the minimum amount $\alpha_{m}^{\prime \prime}>0$ such that $r_{m}^{\prime \prime}\left(\alpha_{m}^{\prime \prime}\right)=\frac{r_{H}+r_{L}}{2}$.

Finally, if projects are financed at a rate $r_{m}^{\prime \prime \prime}(\alpha)$ (specified in $\left.(10)\right)$, the firm obtains

$$
(1-\tau)\left[p^{2} r_{H}+2 p(1-p) \beta \frac{r_{H}+r_{L}}{2}+(1-p)^{2} \beta r_{L}-1\right]
$$

and no equity is used, $\alpha_{m}^{\prime \prime \prime}=0$, as it does not help to reduce the probability of bankruptcy.

We now compare the payoffs in each case. Suppose first that condition (2) is satisfied (part (i) in the statement of the proposition). Then, the payoff when using $r_{m}^{\prime \prime}$ is given by (A14). It can be easily checked that this is always greater than the payoff that can be obtained when using $r_{m}^{\prime \prime \prime}$, (A16). Comparing the payoffs when using $r_{m}^{\prime}$ with those of using 
$r_{m}^{\prime \prime}, r_{m}^{\prime}$ is optimal if and only if

$$
\tau<\bar{\tau}_{m}^{a}:=1-\frac{\left(1-r_{L}\right)}{\left(1-r_{L}\right)+(1-p)^{2}(1-\beta) r_{L}} .
$$

Suppose second that the condition (2) is not satisfied (part (ii) in the statement of the proposition). Then, the payoff when using $r_{m}^{\prime \prime}$ is given by (A15). In this case, $r_{m}^{\prime}$ is preferred to $r_{m}^{\prime \prime}$ as long as

$$
\tau<\bar{\tau}_{m}^{b}:=1-\frac{\left[1-(1-p)^{2}\right] \frac{r_{H}+r_{L}}{2}+(1-p)^{2} \beta r_{L}-r_{L}}{\left(1-\frac{p}{2}\right) p\left[r_{H}-r_{L}\right]},
$$

$r_{m}^{\prime \prime}$ is preferred to $r_{m}^{\prime \prime \prime}$ as long as

$$
\tau<\bar{\tau}_{m}^{c}:=1-\frac{1-\left[1-(1-p)^{2}\right] \frac{r_{H}+r_{L}}{2}-(1-p)^{2} \beta r_{L}}{1-p^{2} \frac{r_{H}+r_{L}}{2}-2 p(1-p) \beta \frac{r_{H}+r_{L}}{2}-(1-p)^{2} \beta r_{L}},
$$

and $r_{m}^{\prime}$ is preferred to $r_{m}^{\prime \prime \prime}$ as long as

$$
\tau<\bar{\tau}_{m}^{d}:=1-\frac{\left(1-r_{L}\right)}{(1-\beta)\left[2 p(1-p) \frac{r_{H}+r_{L}}{2}+(1-p)^{2} r_{L}\right]+\left(1-r_{L}\right)} .
$$

It can be easily shown that the order of these cutoffs is given by $\bar{\tau}_{m}^{b}<\bar{\tau}_{m}^{d}<\bar{\tau}_{m}^{c}$. Therefore, we have the optimal choices claimed in the text. Q.E.D.

Proof of Proposition 14: In this proof, we need to compare the payoffs of joint and separate financing. Suppose first that condition (2) is satisfied (part (i) in the statement of the proposition). If $r_{m}^{\prime}$ is used for joint financing $\left(\tau<\bar{\tau}_{m}^{a}\right)$, then the payoff in joint and separate financing are the same. If $r_{m}^{\prime \prime}$ is used $\left(\tau>\bar{\tau}_{m}^{a}\right)$, then the payoff in joint financing is larger than the payoff of separate financing.

Suppose now that condition (2) is not satisfied (part (ii) in the statement of the proposition). When comparing the cutoffs of joint with that of separate financing, it is easy to show that $\bar{\tau}_{m}^{b}<\bar{\tau}_{i}<\bar{\tau}_{m}^{c}$. Then, we can compare the payoffs in joint and separate financing. First, when $r_{m}^{\prime}$ is optimal in joint financing $\left(\tau<\bar{\tau}_{m}^{b}\right)$, the payoffs are the same in separate and in joint financing. When $r_{m}^{\prime \prime}$ is optimal in joint financing $\left(\bar{\tau}_{m}^{b}<\tau<\bar{\tau}_{m}^{c}\right)$, it is straightforward to check that the payoffs are higher under joint financing if $r_{i}^{\prime}$ is obtained in separate financing, i.e. $\tau<\bar{\tau}_{i}$, but are lower if $r_{i}^{\prime \prime}$ is obtained in separate financing, i.e. $\tau>\bar{\tau}_{i}$. Finally, when $r_{m}^{\prime \prime \prime}$ is optimal in joint financing $\left(\tau>\bar{\tau}_{m}^{c}\right)$, joint financing has lower payoff than separate financing (in separate financing $r_{i}^{\prime \prime}$ would be optimal because $\bar{\tau}_{i}<\bar{\tau}_{m}^{c}$ ). As in the baseline model, the bankruptcy costs are higher under joint financing because of the risk contamination effect. Q.E.D. 


\section{References}

Adams, William James, and Janet L. Yellen, 1976, Commodity bundling and the burden of monopoly, Quarterly Journal of Economics 90, 475-498.

Alderson, Michael J., and Brian L. Betker, 1995, Liquidation costs and capital structure, Journal of Financial Economics 39, 45-69.

Altman, Edward, 1984, A further empirical investigation of the bankruptcy cost question, Journal of Finance 39, 1067-1089.

Armstrong, Mark, 1999, Price discrimination by a many-product firm, Review of Economic Studies, 66, 151-168.

Bannier, Christina E., and Dennis Hänsel, 2008, Determinants of European banks' engagement in loan securitization, Discussion Paper Series 2: Banking and Financial Studies No. 10/2008, Deutsche Bundesbank, Frankfurt/Main.

Bolton, Patrick, and David S. Scharfstein, 1990, A theory of predation based on agency problems in financial contracting, American Economic Review 80, 93-106.

Bond, Philip, 2004, Bank and nonbank financial intermediation, Journal of Finance 59, 2489-2529.

Brealey, Richard A., Stewart C. Myers, and Franklin Allen, 2006, Principles of Corporate Finance (McGraw-Hill Irwin, New York).

Brooks, Chris, and Harry M. Kat, 2002, The statistical properties of hedge fund index returns and their implications for investors, Journal of Alternative Investments 5, 2644.

Campa, Jose Manuel, and Simi Kedia, 2002, Explaining the diversification discount, Journal of Finance 57, 1731-1762.

Cantor, Richard, and Rebecca Demsetz, 2003, Securitization, loan sales, and the credit slowdown, Federal Reserve Bank of New York Quarterly Review, 18, 27-38.

Custódio, Cláudia, 2009, Mergers and acquisitions accounting can explain the diversification discount, Working Paper, London School of Economics. 
Diamond, Douglas W., 1984, Financial intermediation and delegated monitoring, Review of Economic Studies 51, 393-414.

Esty, Benjamin C., 2003, The economic motivations for using project finance, Working Paper, Harvard Business School.

Fang, Hanming, and Peter Norman, 2006, To bundle or not to bundle, Rand Journal of Economics 37, 946-963.

Faure-Grimaud, Antoine, and Roman Inderst, 2005, Conglomerate entrenchment under optimal financial contracting, American Economic Review, 95, 850-861.

Gale, Douglas, and Martin Hellwig, 1985, Incentive-compatible debt contracts: The oneperiod problem, Review of Economic Studies 52, 647-663.

Gorton, Gary, 2008, The panic of 2007, Yale ICF Working Paper No. 08-24.

Gorton, Gary, and Nicholas S. Souleles, 2006, Special purpose vehicles and securitization, in Mark Carey and René M. Stulz, eds.: The Risks of Financial Institutions (University of Chicago Press, Chicago).

Graham, John R., Michael L. Lemmon, and Jack G. Wolf, 2002, Does corporate diversification destroy value?, Journal of Finance 57, 695-720.

Higgins, Eric, and Joseph Mason, 2004, What is the value of recourse to asset-backed securities? A clinical study of credit card banks, Journal of Banking and Finance 28, $875-899$.

Higgins, Robert C, 1971, A pure financial rationale for the conglomerate merger: Discussion, Journal of Finance 26, 543-545.

Higgins, Robert C., and Lawrence D. Schall, 1975, Corporate bankruptcy and conglomerate merger, Journal of Finance 30, 93-113.

Inderst, Roman, and Holger Müller, 2003, Internal versus external financing: An optimal contracting approach, Journal of Finance 58, 1033-1062.

Kale, Jayant, Thomas Noe, and Gabriel Ramirez, 1991, The evidence of business risk on corporate capital structure: Theory and evidence, Journal of Finance 46, 1693-1715. 
Kim, E. Han, 1978, A mean-variance theory of optimal capital structure and corporate debt capacity, Journal of Finance 33, 45-63.

Kim, E. Han, and John McConnell, 1977, Corporate mergers and the co-insurance of corporate debt. Journal of Finance 32, 349-365.

Kleimeier, Stefanie, and William L. Megginson, 2000, Are project finance loans different from other syndicated credits?, Journal of Applied Corporate Finance, 13, 75-87.

Korteweg, Arthur, 2007, The costs of financial distress across industries, Working Paper, Stanford Graduate School of Business.

Korteweg, Arthur, forthcoming, The net benefits to leverage, Journal of Finance.

Leland, Hayne, 2007, Purely financial synergies and the optimal scope of the firm: Implications for mergers, spin-offs and structured finance, Journal of Finance 62, 765-807.

Levy, Haim, and Marshall Sarnat, 1970, Diversification, portfolio analysis, and the uneasy case for conglomerate mergers, Journal of Finance 25, 795-802.

Lewellen, Wilbur G., 1971, A pure financial rationale for the conglomerate merger, Journal of Finance 26, 521-537.

Longstaff, Francis, Sanjay Mittal, and Eric Neis, 2005, Corporate yield spreads: Default risk or liquidity? New evidence from the credit-default swap market, Journal of Finance 60, 2213-2253.

Maksimovic, Vojislav, and Gordon Phillips, 2001, The market for corporate assets: Who engages in mergers and asset sales and are there efficiency gains?, Journal of Finance 56, 2019-2065.

Maksimovic, Vojislav, and Gordon Phillips, 2002, Do conglomerate firms allocate resources inefficiently across industries? Theory and evidence, Journal of Finance 57, 721-767.

Malkiel, Burton G., and Atanu Saha, 2005, Hedge funds: Risk and return, Financial Analysts Journal 61, 80-88.

Mills, Lillian F., and Kaye J. Newberry, 2005, Firms' off-balance sheet and hybrid debt financing: Evidence from their book-tax reporting differences, Journal of Accounting Research 43, 251-282. 
Modigliani, Franco, and Merton Miller, 1958, The cost of capital, corporation finance and the theory of investment, American Economic Review 48, 261-297.

Proschan, Frank, 1965, Peakedness of distributions of convex combinations, Annals of Mathematical Statistics 36, 1703-1706.

Rossi, Stefano, and Paolo F. Volpin, 2004, Cross-country determinants of mergers and acquisitions, Journal of Financial Economics 74, 277-304.

Sarig, Oded, 1985, On mergers, divestments, and options: A note, Journal of Financial and Quantitative Analysis 20, 385-389.

Schoar, Antoinette, 2002, Effects of corporate diversification on productivity, Journal of Finance 57, 2379-2403.

Scott, James H. Jr., 1977, On the theory of conglomerate mergers, Journal of Finance 32, $1235-1250$.

Shaffer, Sherrill, 1994, Pooling intensifies joint failure risk, Research in Financial Services $6,249-280$.

Subramanian, Krishnamurthy, Frederick Tung, and Xue Wang, 2009, Law and project finance, Working Paper, Emory University, Goizueta Business School.

Townsend, Robert M., 1979, Optimal contracts and competitive markets with costly state verification, Journal of Economic Theory 21, 265-293.

Villalonga, Belén, 2004, Diversification discount or premium? New evidence from the business information Tracking Series, Journal of Finance, 59, 479-506.

Warner, Jerold B., 1977, Bankruptcy costs: Some evidence, Journal of Finance 32, 337-347.

Weiss, Lawrence A., 1990, Bankruptcy resolution: Direct costs and violation of priority of claims, Journal of Financial Economics 27, 285-314.

Winton, Andrew, 1995, Costly state verification and multiple investors: The role of seniority, Review of Financial Studies 8, 91-123.

Winton, Andrew, 1999, Don't put all your eggs in one basket? Diversification and specialization in lending, Working Paper, University of Minnesota. 


\section{OMITTED Supplementary Appendix B: Continuous Distribution of Returns}

The analytical characterization of conglomeration provided in the paper is valid for the case with binary returns. This appendix analyzes an extension of the model with continuously distributed returns. The purpose of this extension is threefold. First, this extension allows us to show that the paper's result on bad conglomeration with binary returns are robust to alternative specifications. Second, by comparing our results with those derived through numerical simulations by Leland (2007) in a similar setting with continuous returns, we show the occurrence of bad conglomeration that we discover is novel to the finance literature. Third, in the context of this extension we draw a precise connection with results derived in the industrial organization literature on product bundling.

To retain analytical tractability for this continuous specification, the analysis to follow makes a number of restrictions that are relaxed in the paper for the case with binary returns. Specifically, we assume that bankruptcy costs are extreme and all project's proceeds are lost in case or bankruptcy, so that $\beta=0$. In addition, we focus on our baseline scenario with two identical projects financed uniquely with debt, and without access to equity. By covering a special case of the model analyzed by Leland (2007), we are able to argue that our result on the occurrence of bad conglomeration does not require re-optimizing the capital structure mix in terms of debt and equity. Furthermore, we assume that the returns of each project are symmetrically distributed with a log-concave distribution, as depicted for a normal example in the solid curve in Figure $6 .^{15}$

If the projects are financed separately, the probability of bankruptcy for each of them is equal to the area below the density of returns that lies to the left of the straight line corresponding to the outstanding debt obligation or gross interest rate, which is equal to the amount borrowed plus the net interest obligation demanded by creditors. Perfect competition among risk-neutral creditors drives down this gross interest rate to a level at which creditors expect to exactly recoup the initial investment outlay.

When the projects are financed jointly, the relevant distribution is the dashed curve, representing the distribution of the average returns of the two projects. Note that the distribution of the average of two identically distributed normals is more peaked around the

\footnotetext{
${ }^{15}$ Proposition 15 shows that this logic applies more generally when returns have a symmetric log-concave distribution.
} 


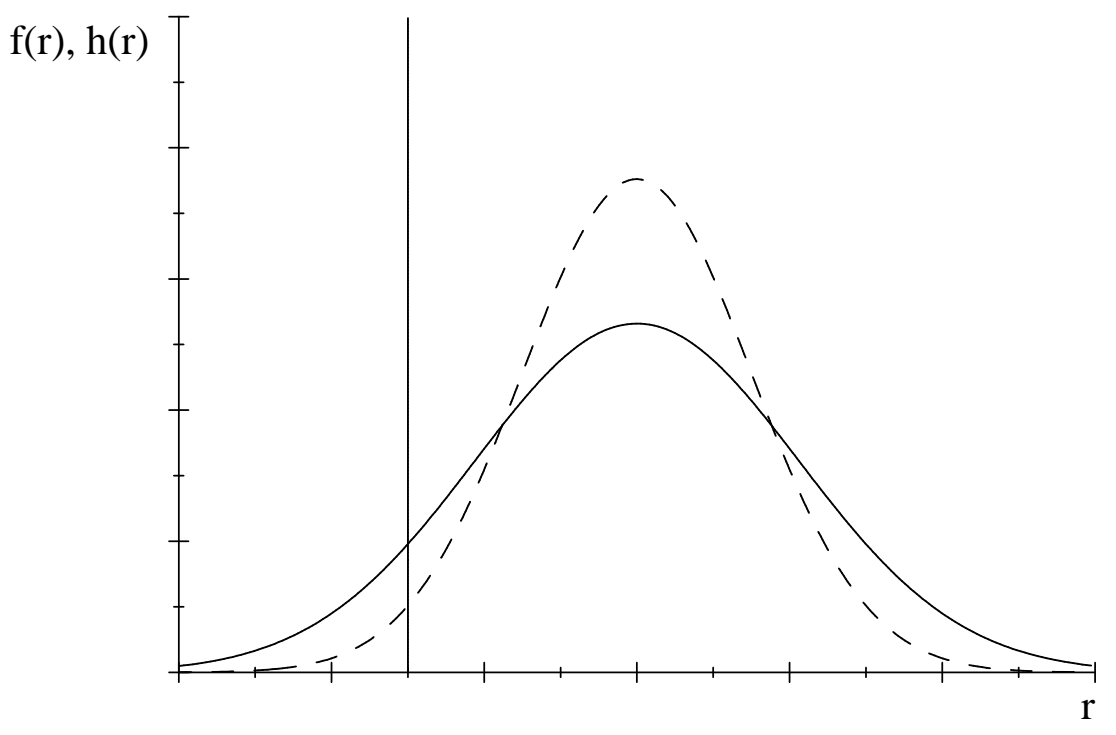

Figure 6. Comparison of Bankruptcy Probabilities for Fixed Interest Rate. The continuous curve represents the probability density of different returns when the projects are financed separately, while the dashed curve represents the density associated to the average return when the projects are financed jointly. The vertical line represents the fixed interest rate. The probabilities of bankruptcy associated to separate and joint financing are equal to the areas below the density and to the left of the interest rate.

mean than the distribution of individual returns. If the interest rate is held constant at the initial level, the probability of bankruptcy is reduced provided that the original gross interest is below the average level of return at which the densities of returns (individual and average) peak, as shown in the figure. Indeed, given that the probability of bankruptcy is reduced by joint financing, creditors are forced to further reduce the gross interest payment, so that the bankruptcy probability at the final equilibrium is even lower. This is essentially the logic that drives Lewellen's (1971) coinsurance benefits from conglomeration.

This result is clearly reversed if instead the original gross interest is above the average return - in this case, the left tail of the distribution is actually higher (rather than lower, as before) under joint than separate financing. When the probability of bankruptcy under separate financing is more than $50 \%$, this probability is further increased under joint financing at the same interest rate prevailing under separate financing. The possibility then arises that there exists a rate below the average return at which the projects can be financed jointly so that, once the interest rate is endogenized, the probability of bankruptcy is again reduced 
when the projects are financed jointly. However, this is not the case when the initial distribution of returns is sufficiently dispersed, in which case conglomeration results in an increase in bankruptcy costs, and thus is unambiguously value-destroying. This Supplementary Appendix provides easy-to-verify conditions on the distribution of returns that determine the value of conglomeration in the presence of bankruptcy costs.

As in Section II, we focus on the case in which a cashless firm needs to finance $n=2$ ex ante identical and independently distributed projects with debt only. We now allow returns to be continuously distributed, but we make the following two additional restrictions to retain analytical tractability:

1. Per-project returns have a continuous density $f\left(r_{i}\right)$ that satisfies (a) log concavity and (b) symmetry around the mean $\mu .^{16}$

2. All returns are lost in case of bankruptcy, $\beta=0 .{ }^{17}$

We illustrate our results for the case with normally distributed returns, where $r_{i} \sim$ $N\left(\mu, \sigma^{2}\right)$ for both $i=1,2$. Given that there are two projects, the firm can either (i) finance each project separately or (ii) finance the two projects jointly. We proceed by first characterizing the conditions for the firm to be able to finance the projects for each of these two financing regimes. Second, we examine which of these two financing regimes generate most profits for the firm, when both options are feasible.

\section{A. Financing Conditions}

Suppose first that the firm finances each project separately. In a competitive credit market, creditors make zero profits. Thus the repayment requested by creditors is defined by

$$
r_{i}^{*}\left[1-F\left(r_{i}^{*}\right)\right]=1 .
$$

\footnotetext{
${ }^{16}$ A random variable is log-concave if the logarithm of the probability density function is concave. Symmetry and log-concavity are satisfied by many common parametric densities, such as the uniform, normal, logistic, Laplace, beta (with $a=b$ ) distribution, and any truncations or linear combinations of these distributions.

${ }^{17}$ Note that if the realized returns are negative, we need to specify whether the creditor is liable when the company defaults. In this case with $\beta=0$, however, no specification is necessary because all returns are destroyed.
} 
The firm's payoff for each project would then be

$$
\int_{r_{i}^{*}}^{\bar{r}} r_{i} d F\left(r_{i}\right)-r_{i}^{*}\left[1-F\left(r_{i}^{*}\right)\right]=\int_{r_{i}^{*}}^{\bar{r}}\left(r_{i}-r_{i}^{*}\right) d F\left(r_{i}\right),
$$

where $\bar{r}$ is the (possibly infinite) upper bound of the support of the return distribution. Given that this is a decreasing function of $r_{i}^{*}$, the firm will select the lowest $r_{i}^{*}$ at which condition (B17) is satisfied, if such a $r_{i}^{*}$ exists. Financing is obtained in such a case.

Next, consider joint financing of the two projects within the same company. Denote by $r_{m}^{*}$ the per project repayment in equilibrium, so that $2 r_{m}^{*}$ is the total repayment promised to investors in return for the initial financing of the two projects, $2 I=2$. Following the same reasoning as before, the firm would select the lowest (if any) per project repayment at which the creditor's zero profit condition is satisfied,

$$
2 r_{m}^{*}\left[1-G\left(2 r_{m}^{*}\right)\right]=2,
$$

where $G$ is the distribution function of the sum of two random variables with distribution $F$. Noting that the distribution of the sum computed at $2 r$ is

$$
G(2 r)=\operatorname{Pr}\left(r_{1}+r_{2} \leq 2 r\right)=\operatorname{Pr}\left(\frac{r_{1}+r_{2}}{2} \leq r\right)=: H(r),
$$

where $H$ is the distribution of the average of $r_{1}$ and $r_{2}$, this condition is equivalent to

$$
r_{m}^{*}\left[1-H\left(r_{m}^{*}\right)\right]=1
$$

Financing is obtained if an $r_{m}^{*}$ that satisfies equation (B21) exists.

For the example with normally distributed returns, Figure 7 represents the parameters (standard deviation $\sigma$ on the horizontal axis and mean $\mu$ on the vertical axis) for which separate and joint financing are feasible. Projects above the red curve and below the blue curve can be financed only jointly. Projects below the red curve and above the blue curve can be financed only separately. Projects below both the red and the blue curves cannot be financed either separately or jointly. Projects above both curves can be financed both separately and jointly.

\section{B. Separate or Joint Finance?}

We now turn to the question of whether separate or joint financing is more profitable for the firm when both financing regimes are feasible.

Proposition 15: Assume that the density $f$ is symmetric around the mean $\mu$ and $\log$ - 


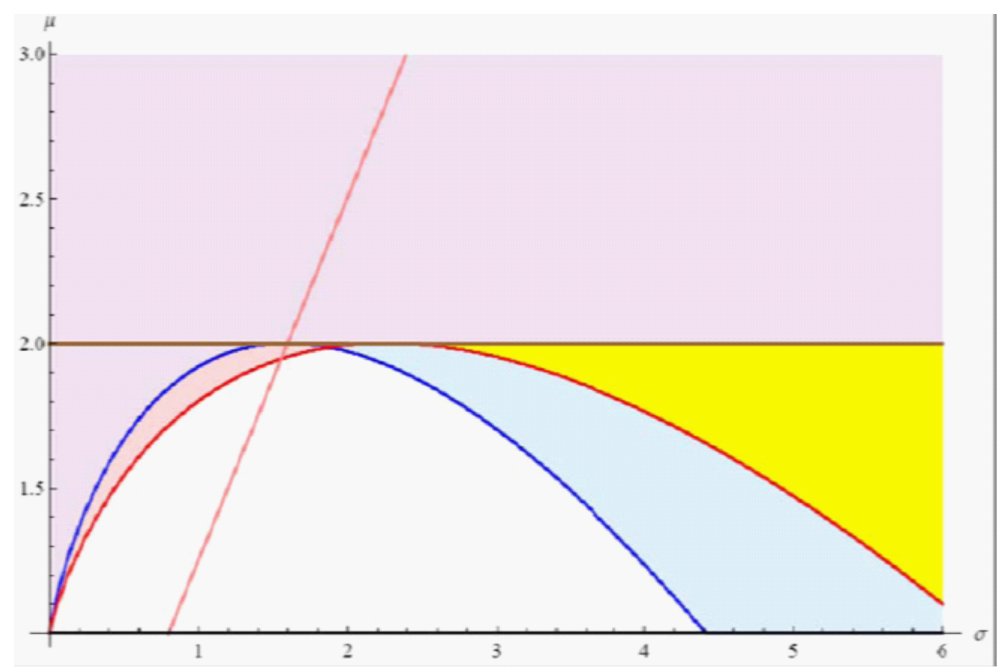

Figure 7. Financing and Optimality Regions with Normally Distributed Returns. Separate (or joint) funding is feasible for $(\sigma, \mu)$ combinations above the blue (or red) curve. Separate financing dominates joint financing for $(\sigma, \mu)$ combinations above the red and blue curves and below the brown and the pink lines, which depict the two inequalities for optimal separation.

concave; realizations are independent and the bankruptcy recovery rate is $\beta=0$. If the firm can finance the projects both separately and jointly, then it should finance them separately if

$$
\mu<2 \text { and } h(\mu) \mu<1 / 2 .
$$

Proof. From Proschan (1965), we know that if two independent random variables have a log-concave and symmetric density, then the average distribution, which we denote by $H$, is more peaked than the distribution of the individual random variable, which we denote by $F$. As a consequence, the distribution of the individual random variable and that of the average cross at $r=\mu$, and we have

$$
F(r) \gtreqless H(r) \Leftrightarrow r \lesseqgtr \mu
$$

and as a result

$$
r[1-F(r)] \lesseqgtr r[1-H(r)] \Leftrightarrow r \lesseqgtr \mu .
$$

If $r_{m}^{*}$, the lowest $r$ such that $r[1-H(r)]=1$, is such that $r_{m}^{*}<\mu$, then $r_{m}^{*}<r_{i}^{*}$. Indeed, although $r_{i}^{*}$ exists by assumption, it is not possible that $r_{i}^{*}<r_{m}^{*}$ because, by (B23) and concavity of the profit function, we have that for $r<r_{m}^{*}, r[1-F(r)]<r[1-H(r)]<$ 
$r_{m}^{*}\left[1-H\left(r_{m}^{*}\right)\right]=1$. As a result, from (B22) and monotonicity of $F$, we conclude that the probability of bankruptcy is lower with joint financing, $H\left(r_{m}^{*}\right)<F\left(r_{m}^{*}\right)<F\left(r_{i}^{*}\right)$.

On the other hand if $r_{m}^{*}$ is such that $r_{m}^{*}>\mu$, then $r_{m}^{*}>r_{i}^{*}$. Indeed, given that the creditor's proceeds at $r=0$ are equal to 0 and they are higher than 1 at $r=r_{m}^{*}$, $r_{m}^{*}\left[1-F\left(r_{m}^{*}\right)\right]>r_{m}^{*}\left[1-H\left(r_{m}^{*}\right)\right]=1$, by the intermediate value theorem there exists some $r_{i}^{*}<r_{m}^{*}$ at which $r_{i}^{*}\left[1-F\left(r_{i}^{*}\right)\right]=1$. As a result, from (B22) and monotonicity of $H$, we have that the probability of bankruptcy is lower with separate financing, $F\left(r_{i}^{*}\right)<H\left(r_{i}^{*}\right)<H\left(r_{m}^{*}\right)$.

By single-peakedness, $r_{m}^{*}$ is such that $r_{m}^{*}>\mu$ if and only if the following two conditions hold

$$
\left.\frac{\partial r[1-H(r)]}{\partial r}\right|_{r=\mu}>0 \text { and }\left.r[1-H(r)]\right|_{r=\mu}<1,
$$

which are equivalent to

$$
h(\mu) \mu<\frac{1}{2} \text { and } \mu<2,
$$

as claimed.

For the example with normally distributed returns, $r_{i} \sim N\left(\mu, \sigma^{2}\right)$, the conditions for separate financing are

$$
\mu<2 \text { and } \mu<\sigma \sqrt{\pi} / 2
$$

These conditions identify the region of parameters for which bad conglomeration arises in Figure 7. In the context of numerical results derived for normally distributed, Leland (2007) argues that the possibility of bad conglomeration arises because of the endogenous choice between debt and equity. Instead, our analytical conditions characterizes when bad conglomeration arises also when financing is only through debt. We conclude that bad conglomeration arises regardless of the endogenous choice between debt and equity, a result that was not envisioned in Leland's (2007) numerical analysis.

Finally, we turn to the connection between this problem of project bundling and the problem of product bundling analyzed in a voluminous literature in industrial organization, pioneered by Adams and Yellen (1978) and recently advanced by Fang and Norman (2006). A profit maximizing monopolist sells $N=2$ indivisible products indexed by $i=1,2$. Consumers' valuation (a.k.a. reservation price) for product $i, r_{i}$, is distributed as a continuous random variable with density $f\left(r_{i}\right)$ and distribution $F\left(r_{i}\right)$. Setting product $i$ 's cost to zero for simplicity, monopoly profits are equal to revenues. Suppose that products are independent 
in consumption, so that consumers' valuation for the bundle consisting of the two products is equal to the sum of the valuations for the component products, $r_{1}+r_{2}$. Focus on the problem of pure bundling: Does the monopolist achieve higher profits selling the two products separately or jointly?

The maximized profits achieved by the monopolist with separate products are

$$
p_{i}\left[1-F\left(p_{i}\right)\right],
$$

where $p_{i} \in \arg \max \{r[1-F(r)]\}$, given that the demand at price $p$ is equal to $1-F(p)$. Defining the distribution $H(r)$ of the average of $r_{1}$ and $r_{2}$ as in (B20), the maximized perproduct profits achieved by the monopolist with bundled products are

$$
p_{m}\left[1-H\left(p_{m}\right)\right]
$$

where $p_{m} \in \arg \max \{r[1-H(r)]\}$ is the profit maximizing price for each element of the bundle. Note that (B24) and (B25) are equal to the left-hand sides of equation (B17) and (B21) respectively. The parallel between project and product bundling is now apparent. In light of this connection, Proposition 9 can be seen as a project bundling analogue of Armstrong's (1999) limit result on the optimality of bundling a large number of products. 